\title{
JOURNAL OF AL AZHAR UNIVERSITY ENGINEERING SECTOR "THE COMMON CHARACTERISTICS OF THE GREAT DESERT ARCHITECTURE THE ENVIRONMENTAL APPROACH TO DESIGN IN DRY HOT REGIONS "
}

\author{
Alaa El-deen Abd AL-Rhman Ebrahem Abozeid \\ Architectural Engineering Department, Faculty of Eng., Al-Azhar University, Cairo, Egypt \\ E-mail: alaaaboeyad@gmail.com
}

\begin{abstract}
The paper discusses a number of common factors in the architecture of the great Desert, which forms the features and characteristics of this architecture,

Which are essentially environmental and cultural factors and similarities in construction methods and building materials, Due to similar climatic conditions and cultural assets in most regions, The research aims at studying these factors through studying several basic points:

-Monitoring and analysis of the most important features and elements of architectural heritage in the urban areas in the great desert region in Africa at the level of building and urban assembly.

-Study of building materials and methods of construction.

- Foundations of sustainable environmental design derived from architecture and environmental urbanization in the great desert regions.

- Design and planning of new urban communities in the hot, dry desert areas.

The role of the functional performance of the desert environment, and how to achieve this in a modern style. Through the study and analysis of three case studies representing three different cultures of three regions of the African great desert region, The first city of Gherdaia in the valley of Mesab in Algeria, And the second village of Al-kasr in Dakhla Oasis in Egypt, And the third city Agades or (Agadez) in Niger, They represent examples of the heritage of the Great Desert, And to benefit from them in studying the foundations of the design and planning of communities with a hot desert nature, An image that corresponds to the changes of the age, And how to merge the old and the modern in the form of modern environmental architecture through an executable model.
\end{abstract}

Key words ; The hot dry areas/ The great desert/ Eco- design/ Building materials/ Methods of construction

$$
\begin{aligned}
& \text { السمات المشتركة لعمارة الصحراء الكبرى المدخل البيئي للتصميم فى المناطق الحارة الجافة } \\
& \text { علاء الدين عبد الرحمن إبراهيم أبو زيد }
\end{aligned}
$$

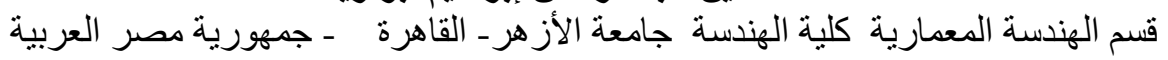

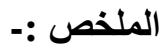

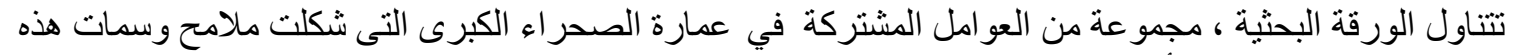

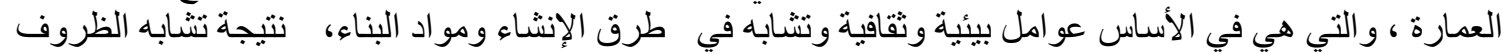

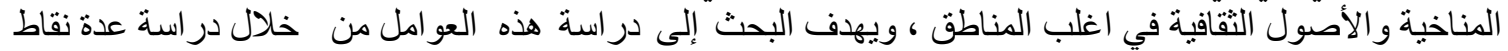

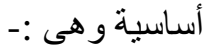




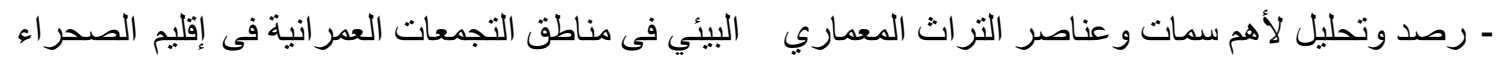

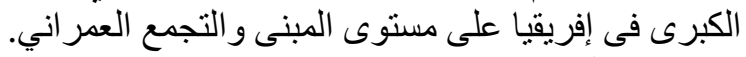
- در اسة مو اد البناء وطرق الإنياء الإنشاء.

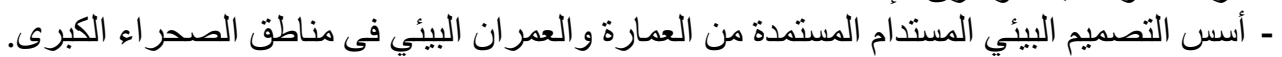

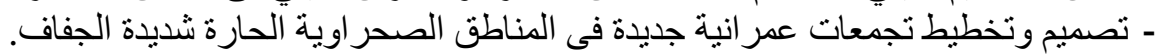

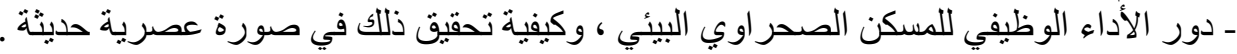

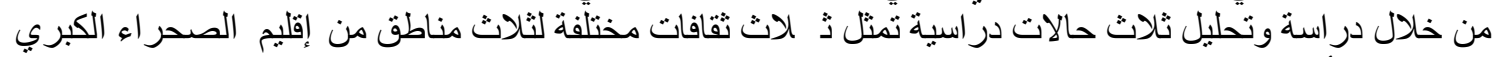

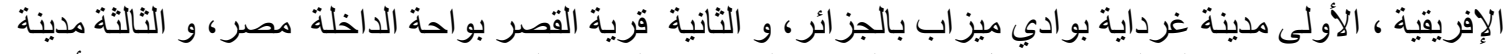

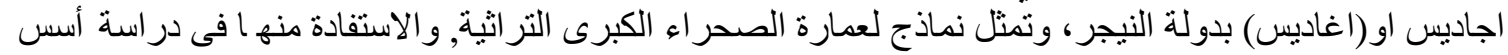

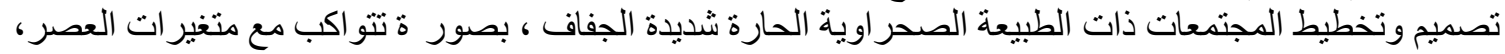

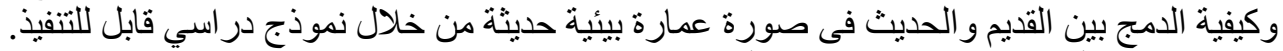
الكلمات المفتاحية : المناطق الحارة الجافة / الصحر اءع الكبرى / التصميم البيئي / مواد البناء /طئة الطرق الإنشاء

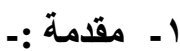

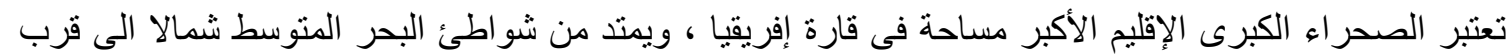

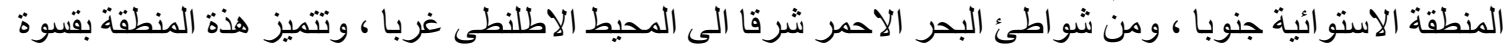

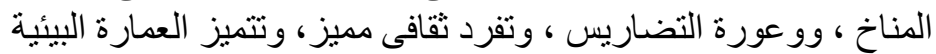

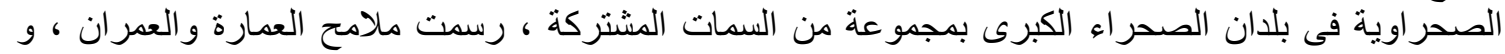

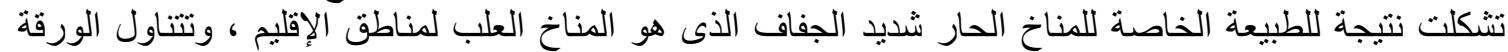

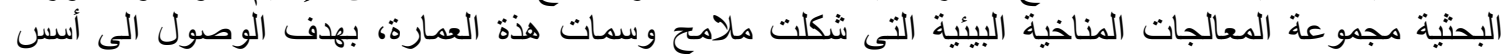

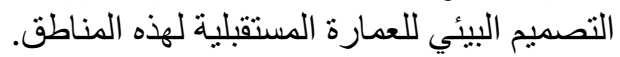

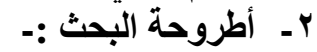

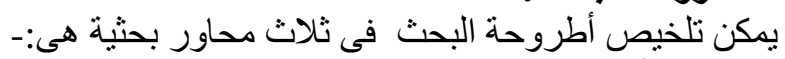

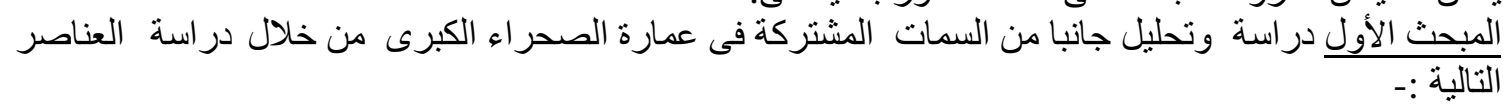

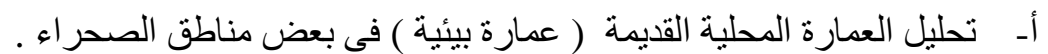

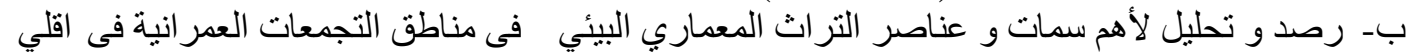

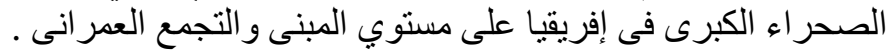

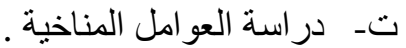

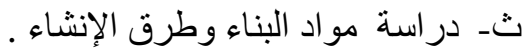
ا ـ الوقوف على أسس التصميم البيئي المستدام المستمدة والـ مستنبطة من دراسة المبحث الاول وإمكانية

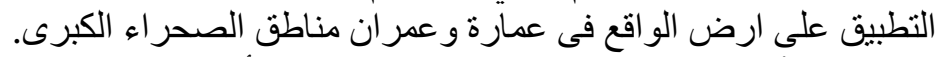

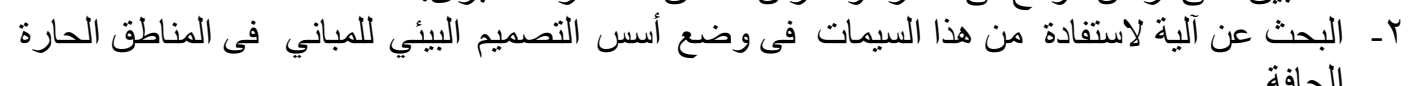
المبحث الثالث إيجاد نموذج در اسي مقترح قابل للتطبيق للعمارة الصحر اء الحديثة فى مناطق الصحر اء الكبرى من

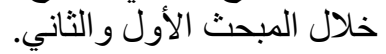

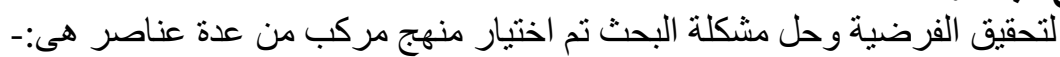

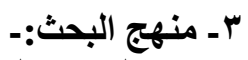

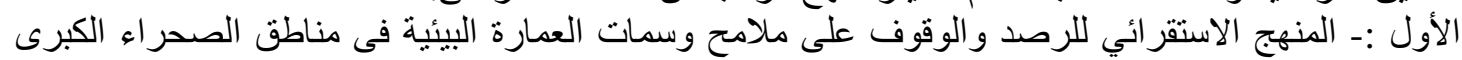

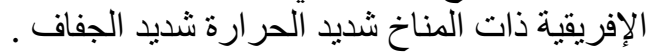

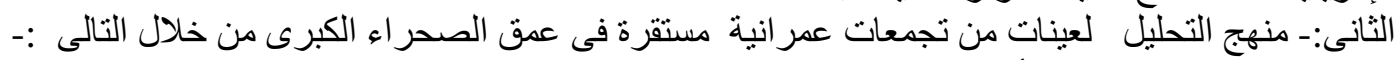

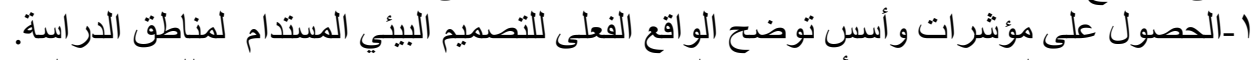

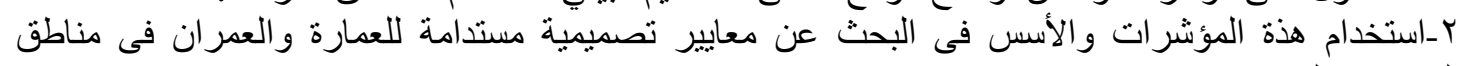

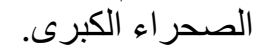
الثالث المنهج الإستتمباطى وذلك من خلال المنهج الأول والثاني استنباط نموذج قابل لتطبيق يكون ذو مرجعية

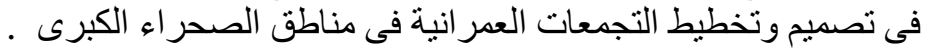


ع -مصطلحات البحث :- -

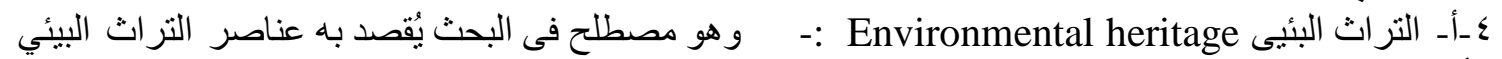

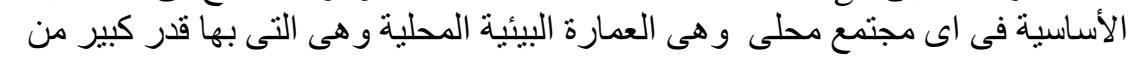

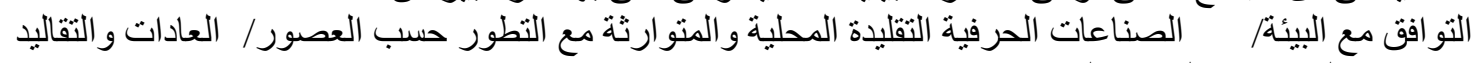

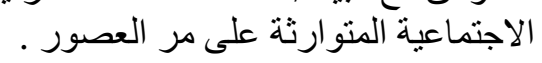

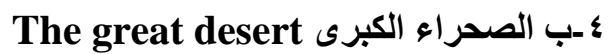

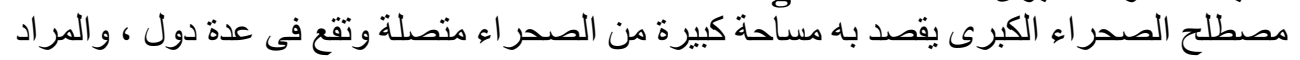

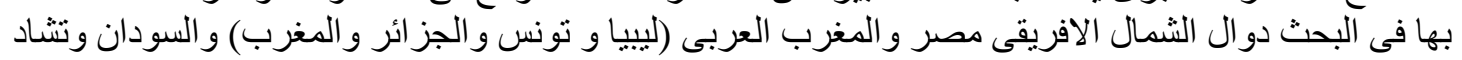

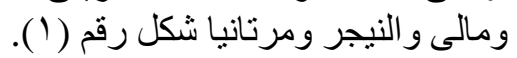
ع ـت المناطق الحارة الجافة The hot dry areas:

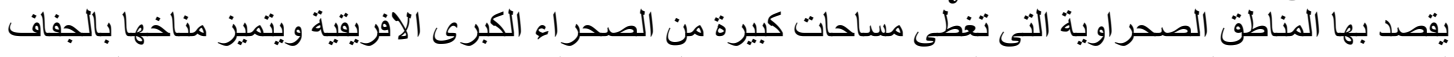

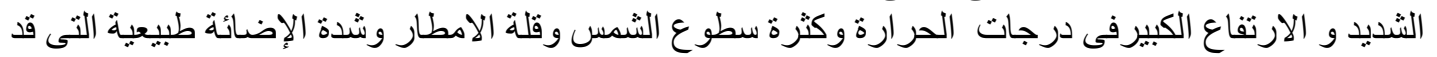
تصل الى اكثر من خمسون الف لفئ لكس.

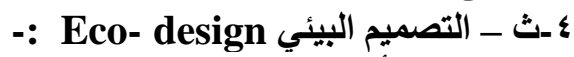

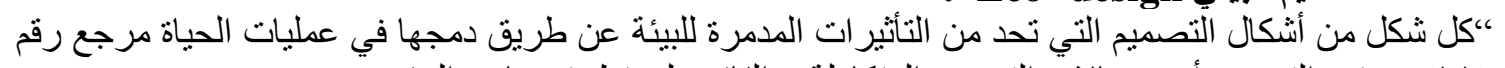
(11) (11) ويعتبر التصميم أحد مجالات التصميم المنكاملة ،و القائم على تطبيق مبادئ البيئي
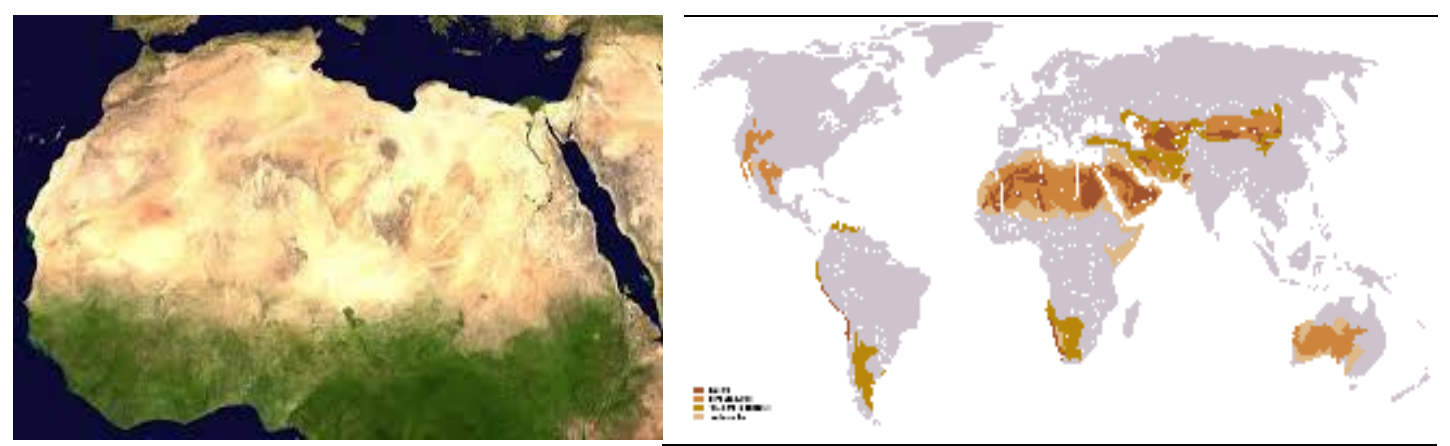

شكل رقم ( ) خريط توزيع المناطق الصحراوية وشبة الصحراوية حول العالم المصدر ويكيبيليا / صورة جوية من موقع جوجل ارث لمناطق الصحراء الكبرى الافريقية.

الإستدامة والتى تعتمد على ترشيد الطاقة وتدوير النفايات و مبادئ العمارة الخضية الخضر اءؤ.

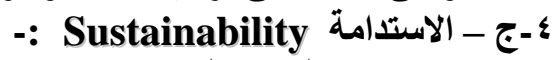

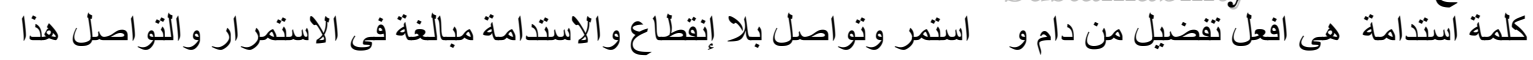

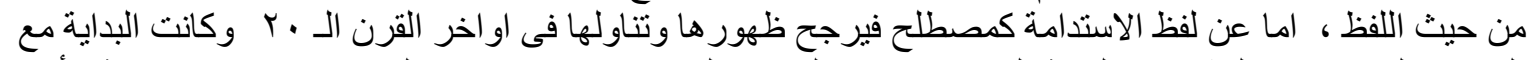

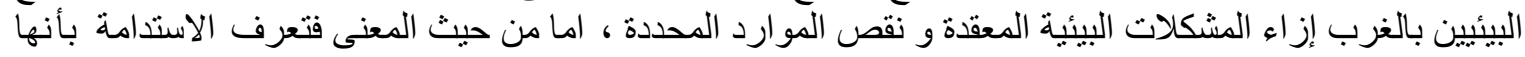

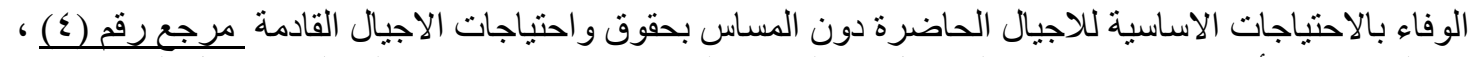

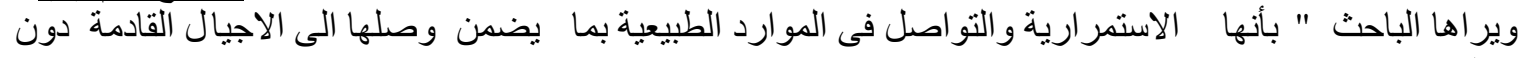
انقطاع اوتغيير ". هـ السمات المناخية لمناطق الصحراء الكبرى الكبر:-

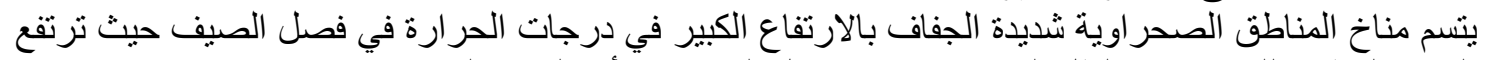

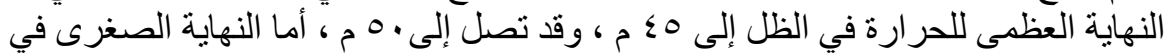

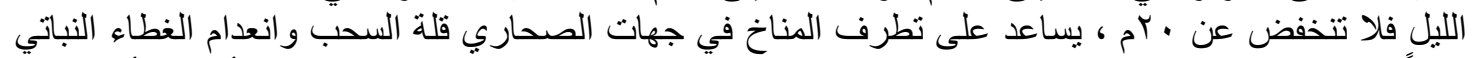

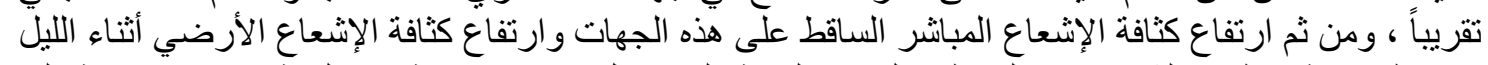

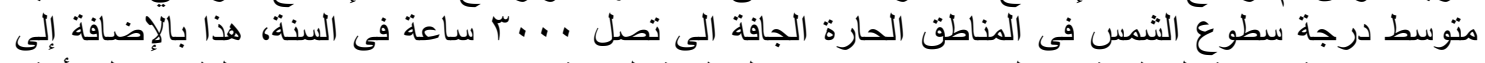

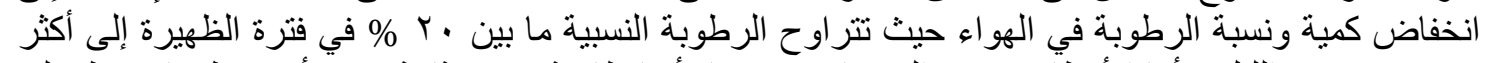

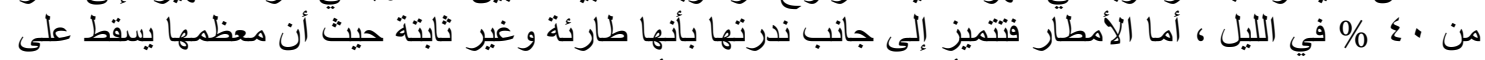

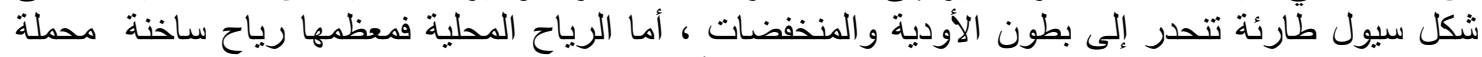

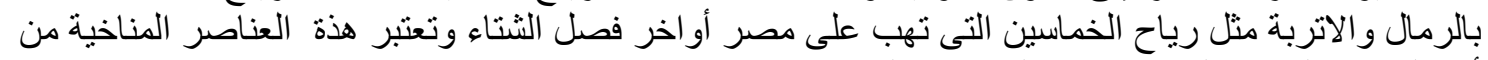

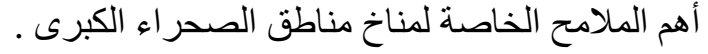


7ـ دور الأداء التوظيف للمسكن الصحراى فى التظلب على الظروف المناخية القاسية .

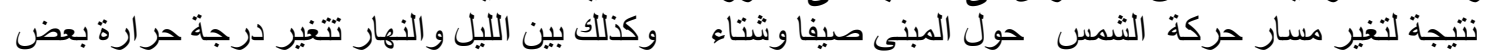

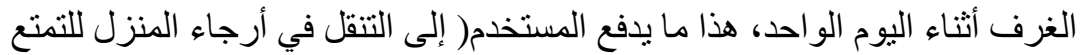

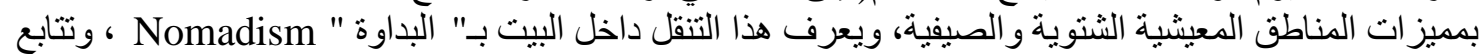

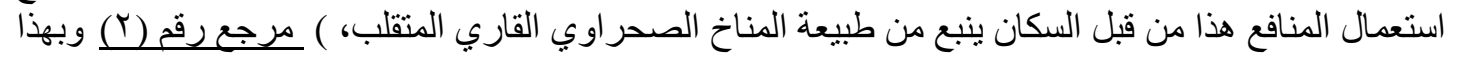

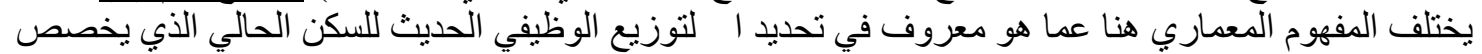

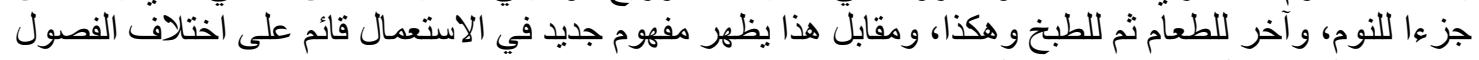

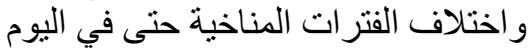

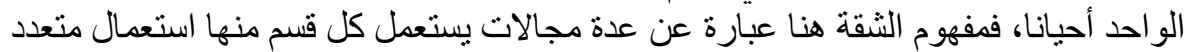

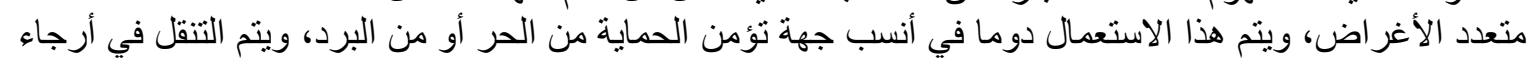

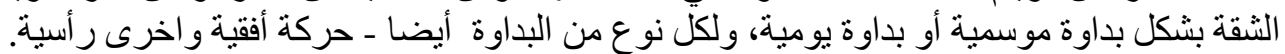

c
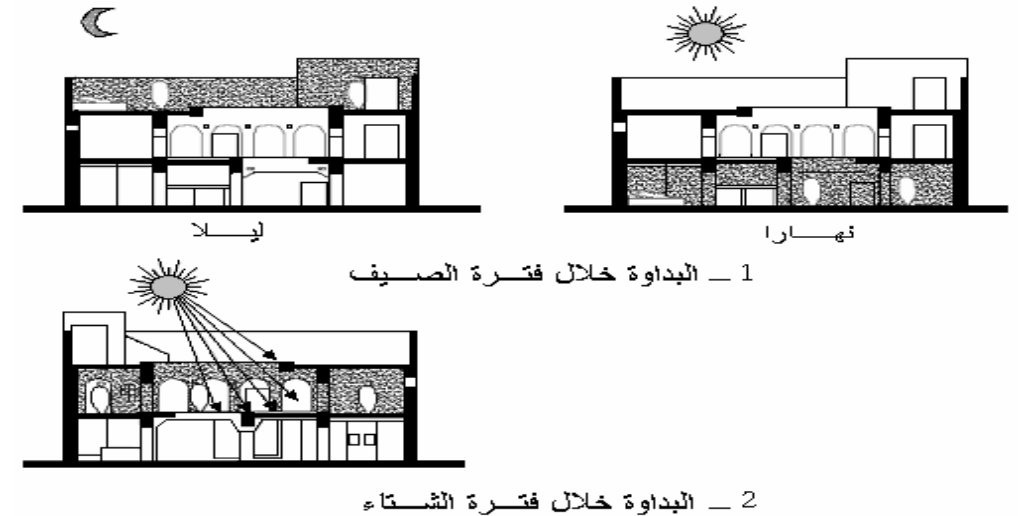

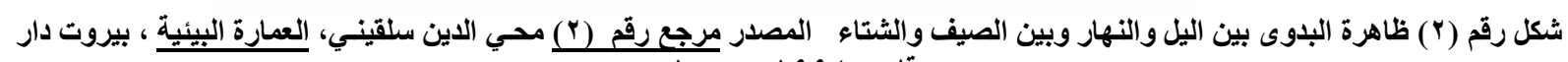

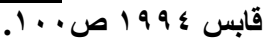

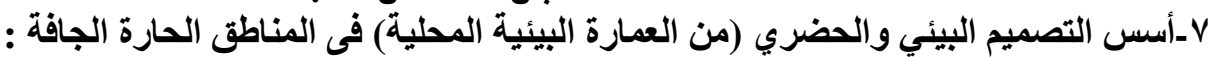

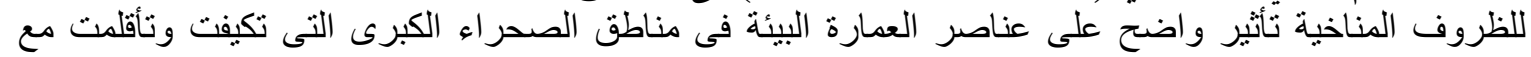

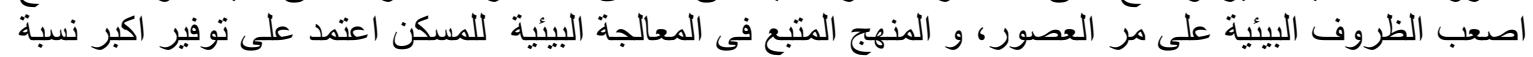

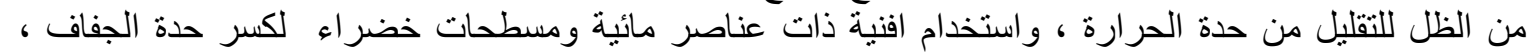
و استخدام مواد بناء لها القدرة عى العزل الئل الحرارة الجى وتحقيق خاصية ، التخلف الزمى وفيما يلى الهم عناصر التصميم

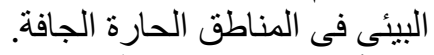

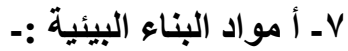

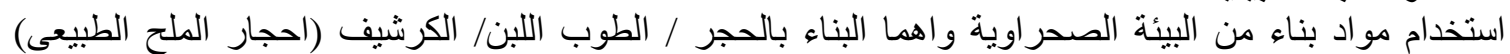

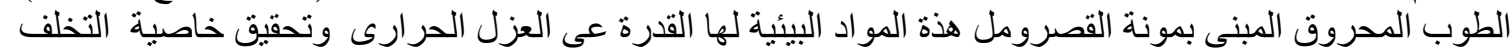

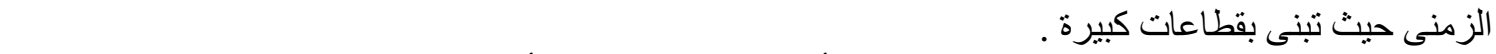

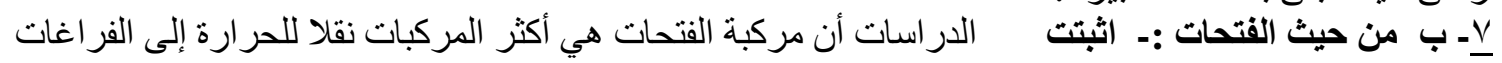

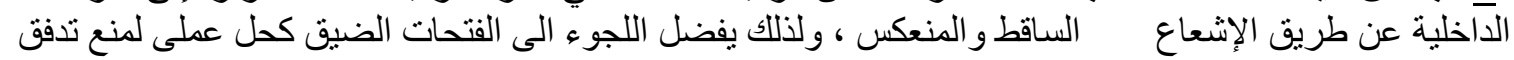

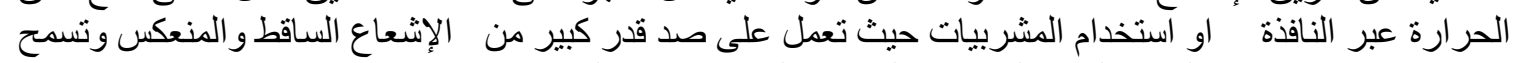

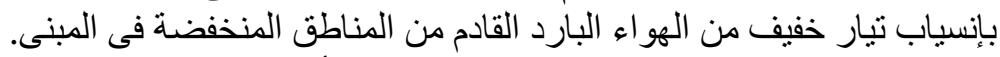

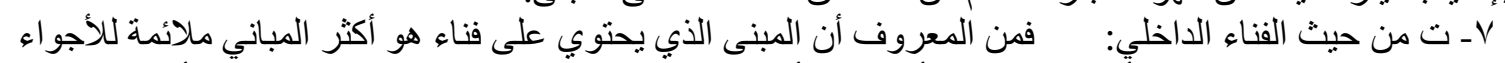

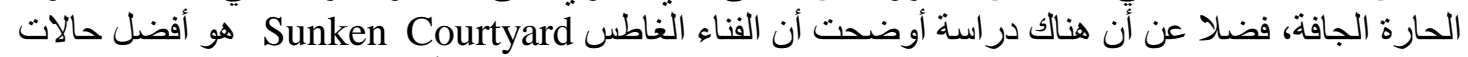

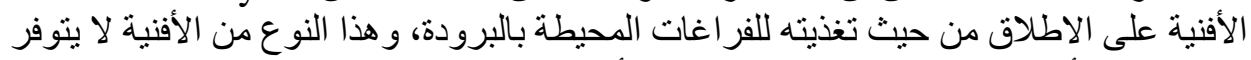

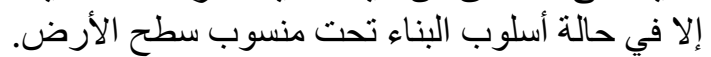

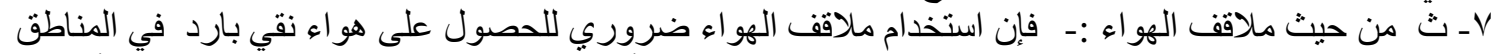

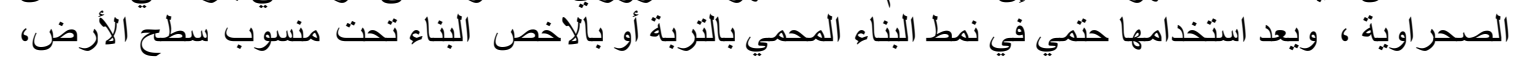

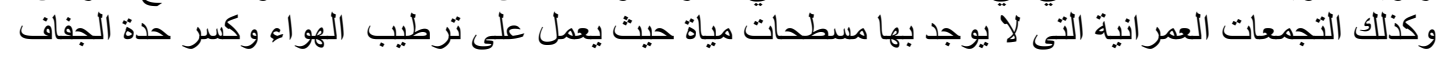

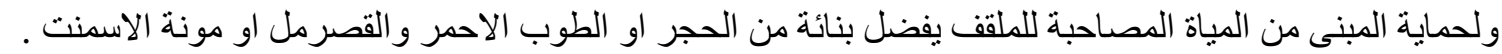

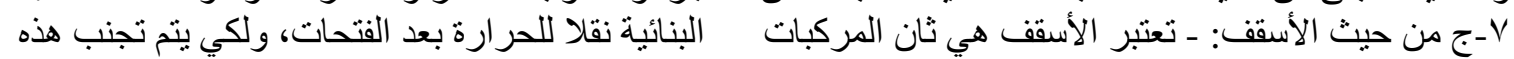

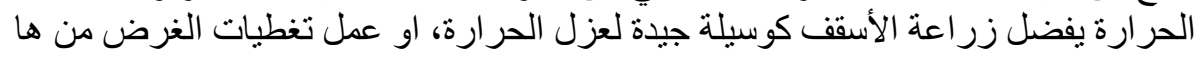


خلق ظلال عن طريق الاسقف المزدوجة يكون الاول انشائى و الثانى للحماية من اشعة الثمس بينهما فرغ غ بسيمح

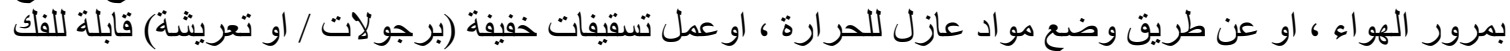

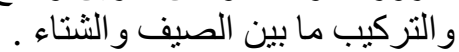
1-الحالات الاراسية مئة

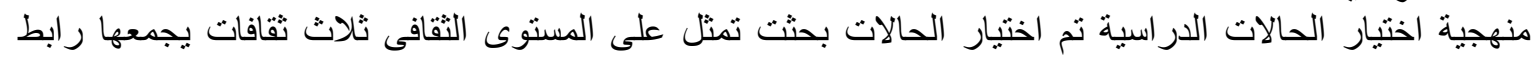

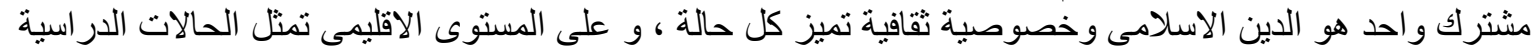

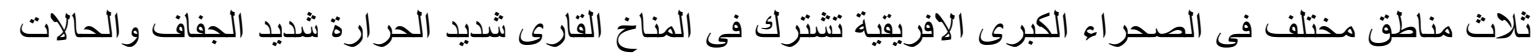

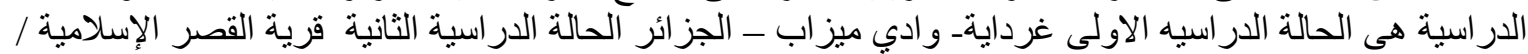

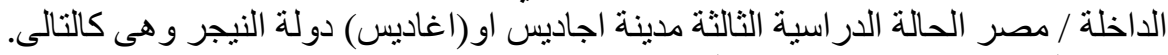

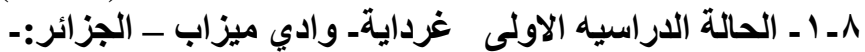

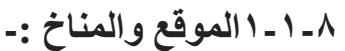

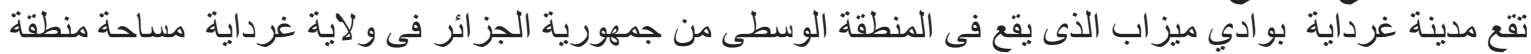

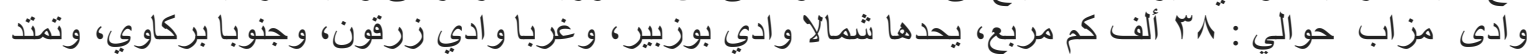

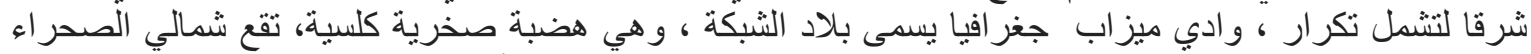

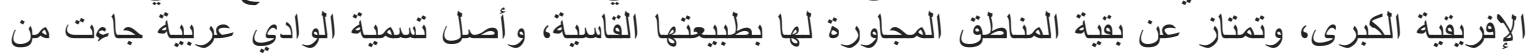

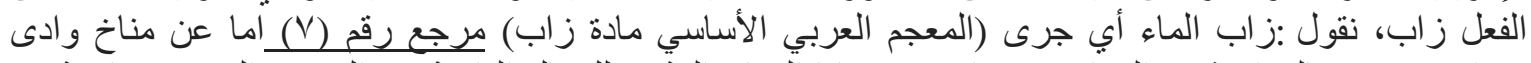

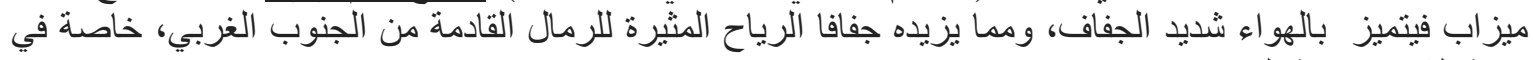

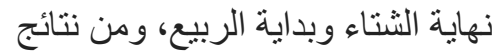

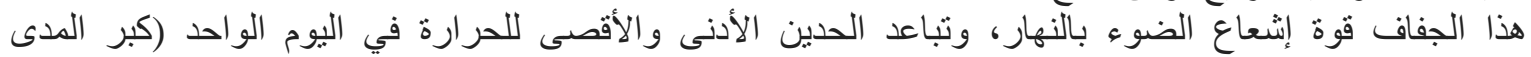

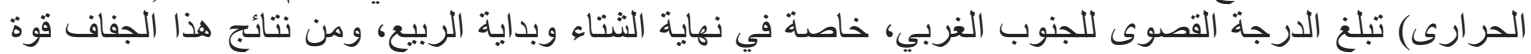

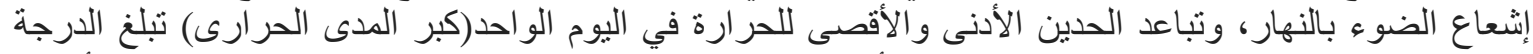

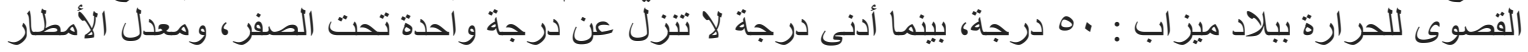

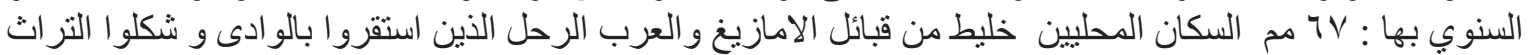

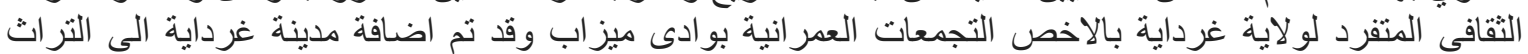

يتسم تخطيط البلدة القديمة لمدينة غرداية على النسيج العضوى المتجة النى الى مركز البلدة وهو من النسيج المنضام

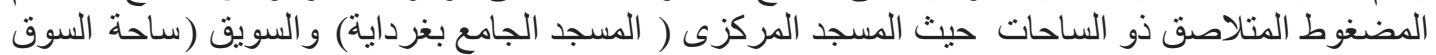

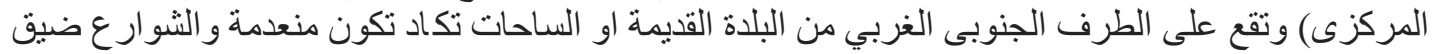

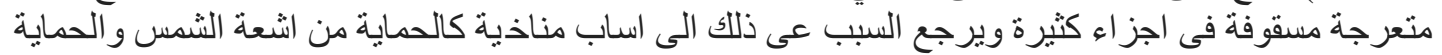

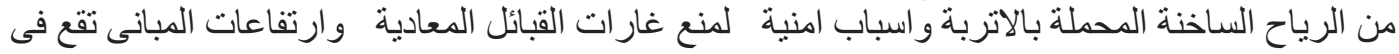
نطاق الطابيقين . ن أرن
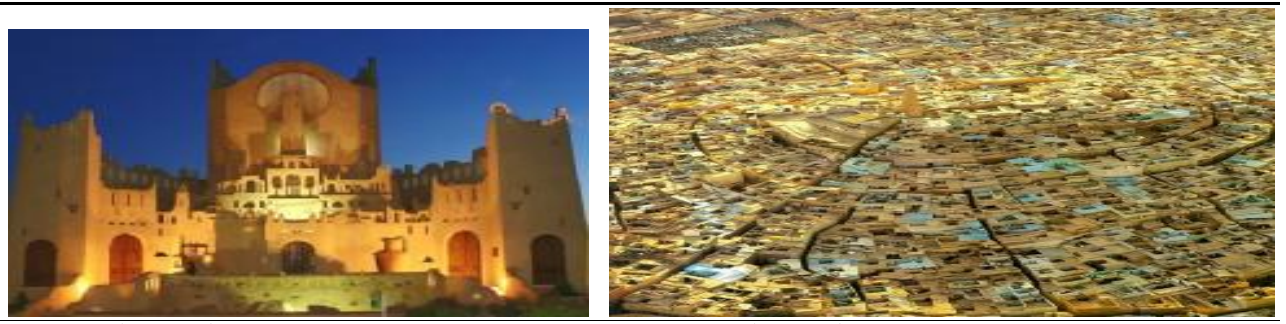

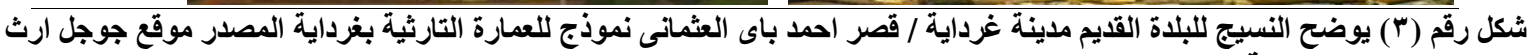

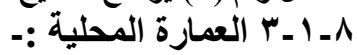

عند النظر الى المسكن بمدينة غردايا ويظهر فيه خضوع المئه المبنى بشكل كامل للتعاليم الإسلامية التّمحة، و المنازل تتميز

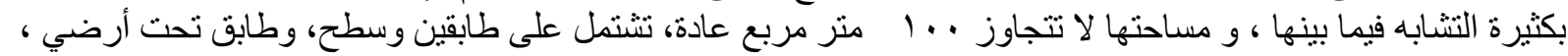

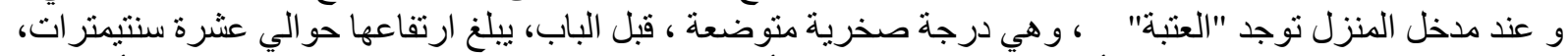

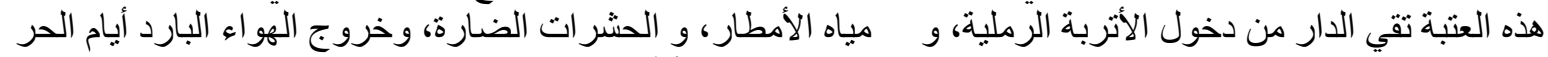

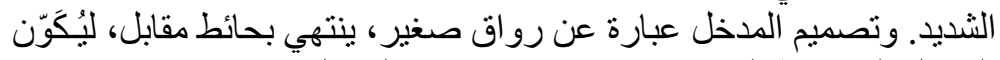

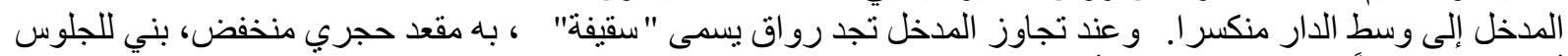

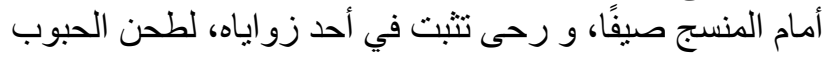




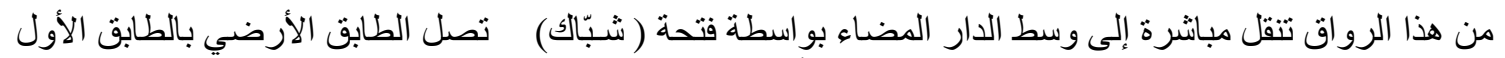

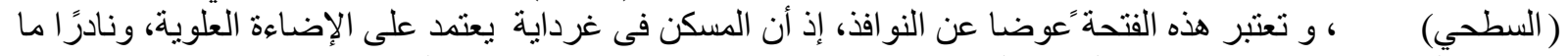

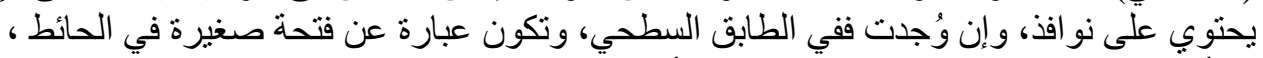

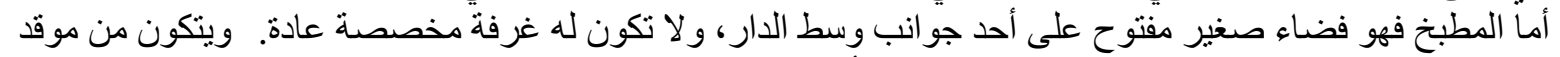

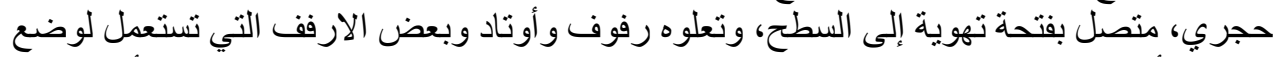

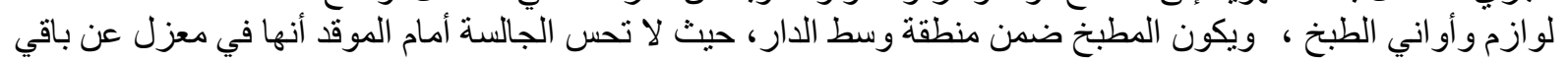

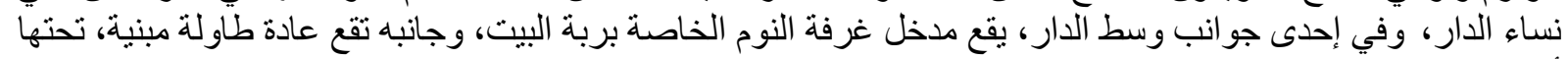

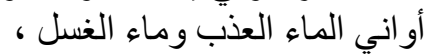

ويخصص الطابق الأرضي، لاستقبال النساء نهارًا عادة، أما الطابق الأول، و هو الطابق السطحي، فيصعد إليه

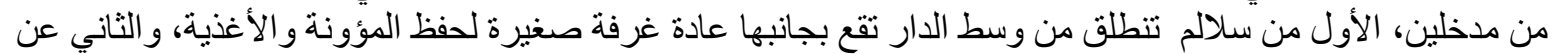

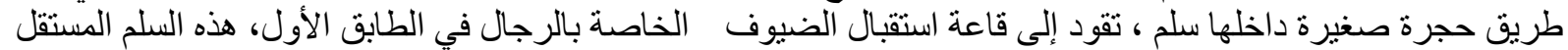

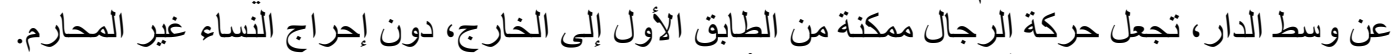

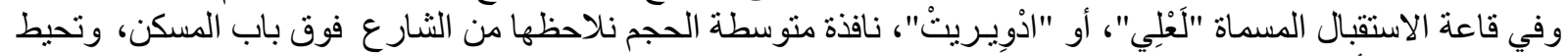

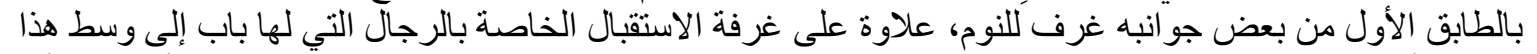

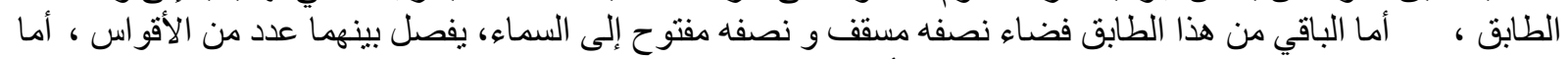

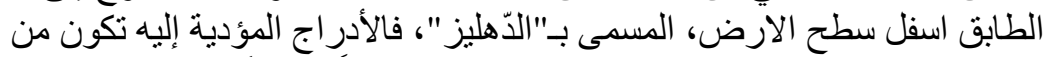

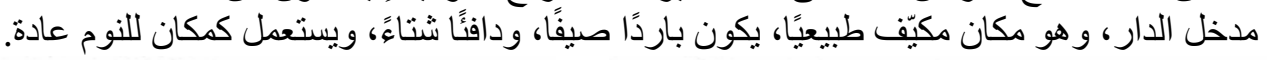

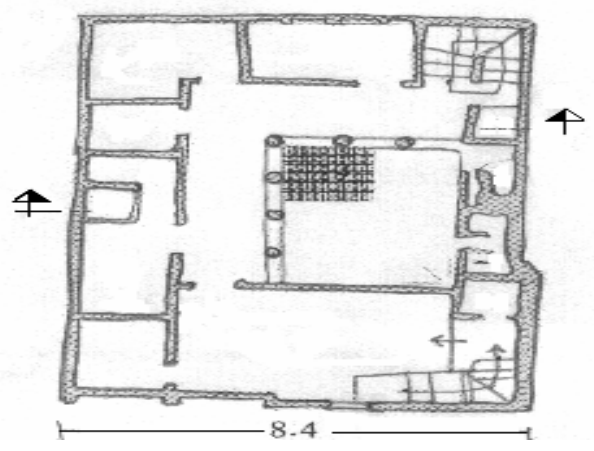

مسقط أفقي للاور الأول

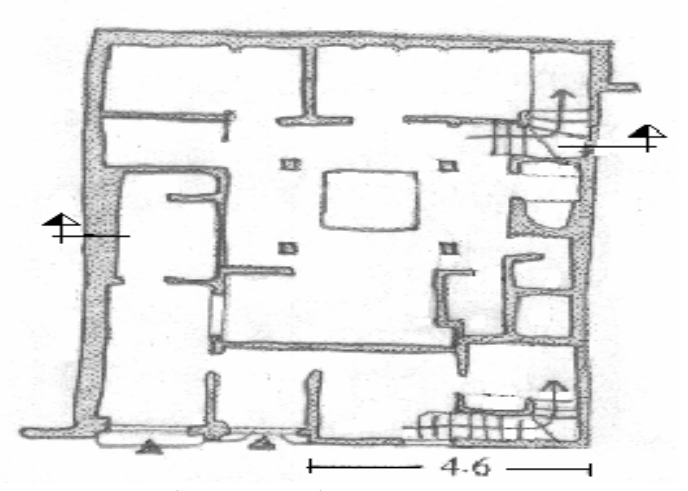

مسقط أفقي للاور الأرضي

شكل( ؛ ): يوضح مسكن بغردايةـ وادي ميزاب_الجزائرعمارة محلية.

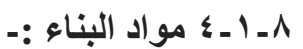

استخدم سكان و ادى ميز اب مو اد البناء المحلية المتوفرة في الطبيعة، لتناسبها مع متطلبات المتانة و العزل دون إهمال

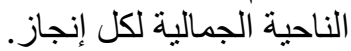

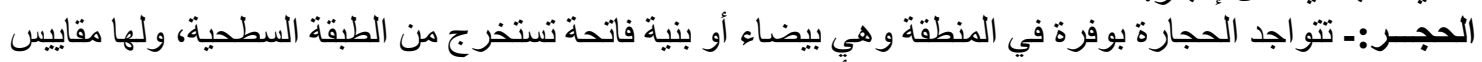

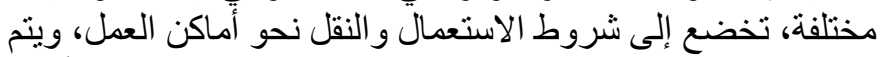

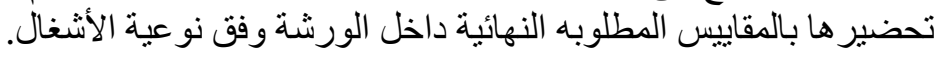
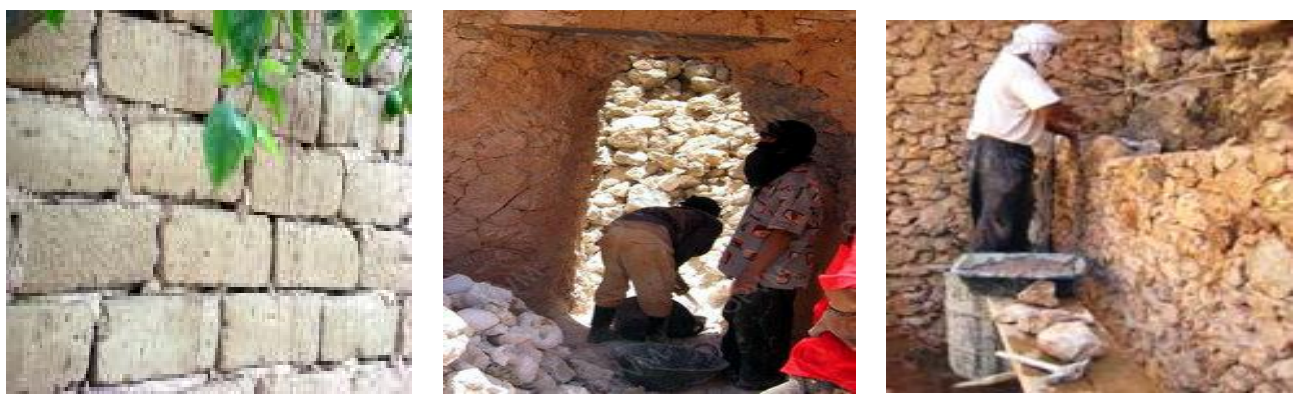

شكل رقم (0) استخدام مو اد النهو البيئة فى مبانى غرداية

-7 -

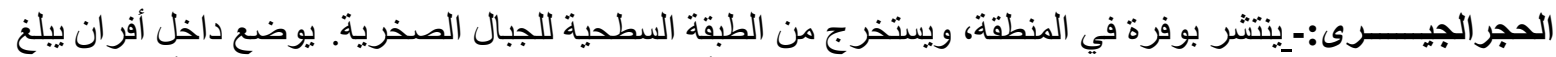

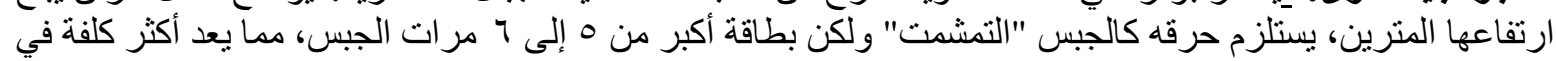




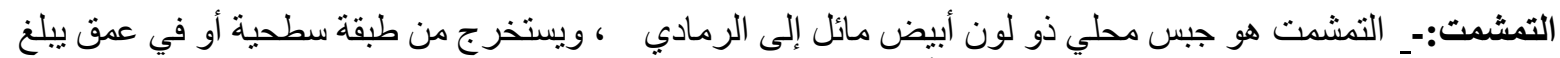

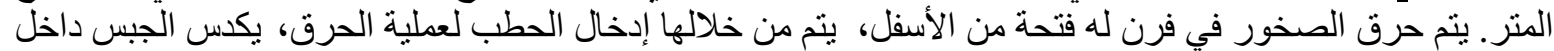

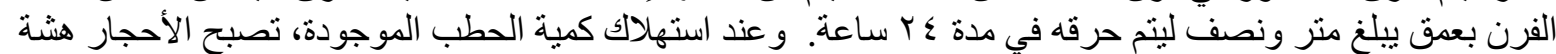

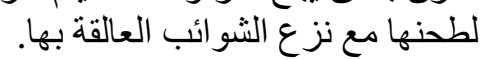

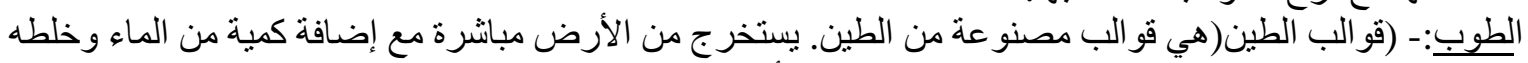
وصنع قو الب، ثم تترك لتجف تحت الثمس. وفي بعض الأحيان يضاف مع الخليط كمية من التبن لتقويته.

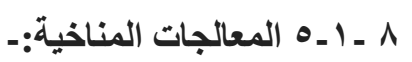

تقوم المعالجات المناخية لمساكن غرداتية على على تتحقق ظاهرة البداوة اليومية في أوقات الصيف عندما يستخدم السكان

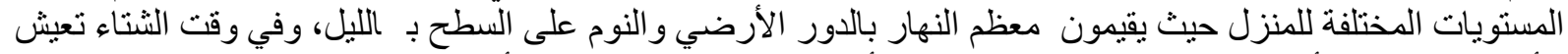

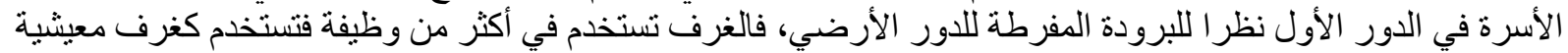

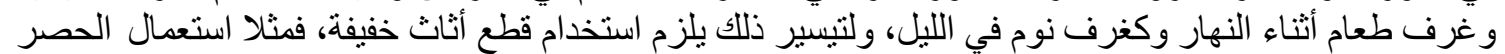

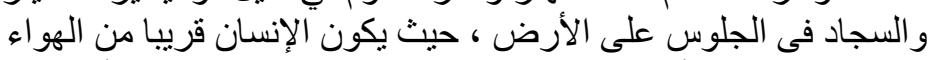

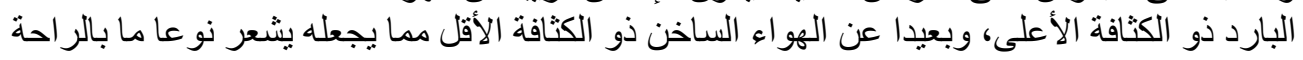

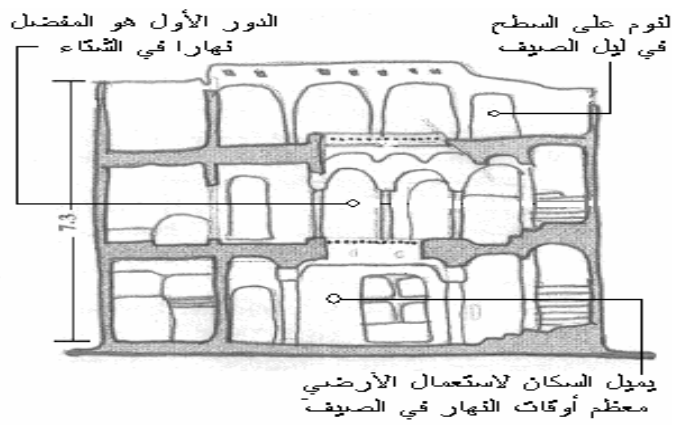

قطاع رأسي في جسم المسكن

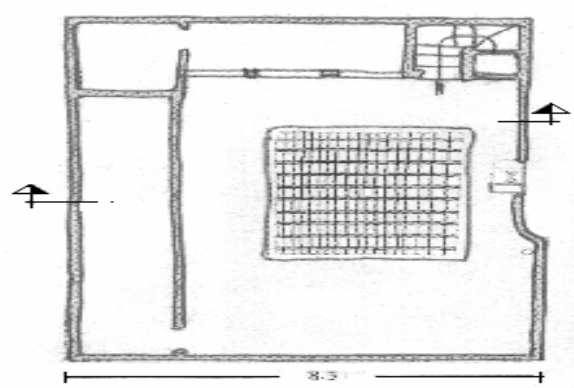

مسقط أفقي لاور السطح

شكل(ף): يوضح مسكن بغرداية_ وادي ميزاب_الجزائر المصدر مرجع رقم (V) أسكان الاغلبيى بتوشكى مرجع سابق سابق،

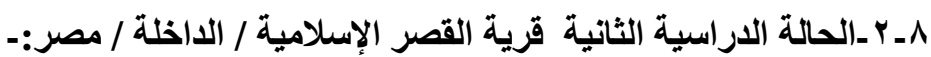

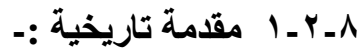

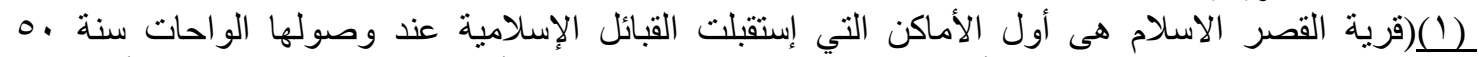

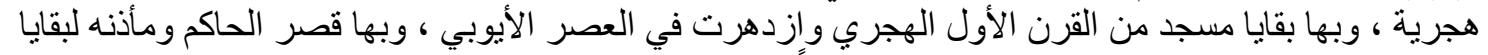

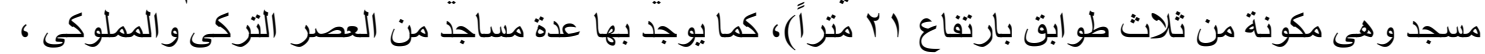

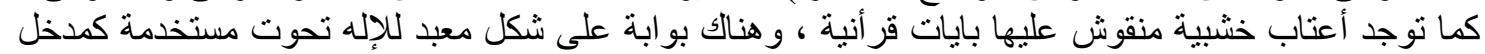

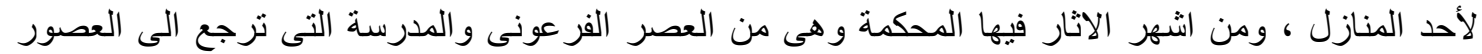

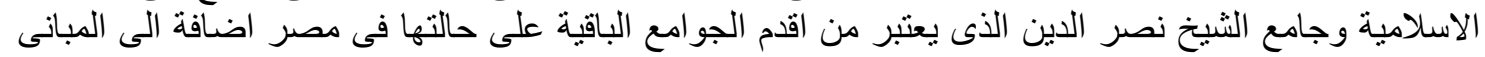

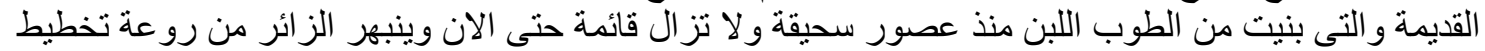

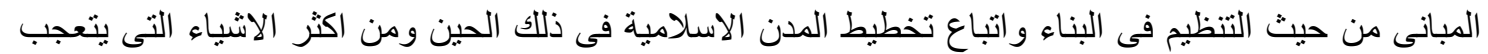

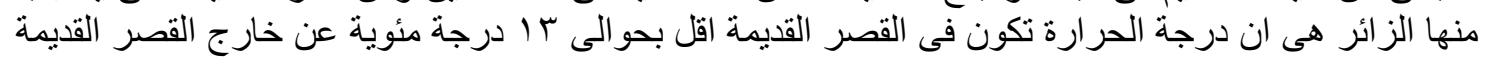

الثيء يدل على وقدرة سكان هذه القرية الذين تمكنو ا من تسخير الطبيعة لصالحهم .
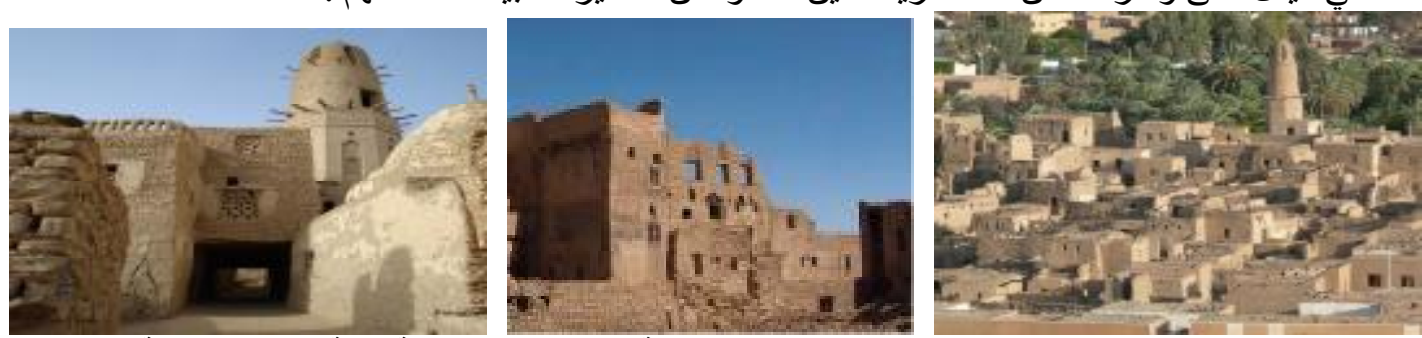

شكل رقم (V) الصور توضح النسيَج العام والعمارة المحلية وبعض الحرَت البيئية لقرية القصر الاسلامية

المصدر موقع مصريات. 


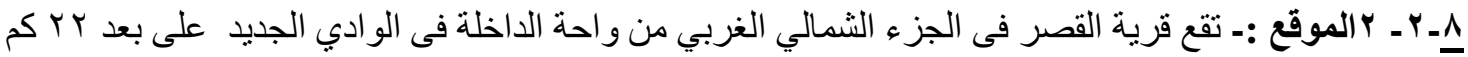

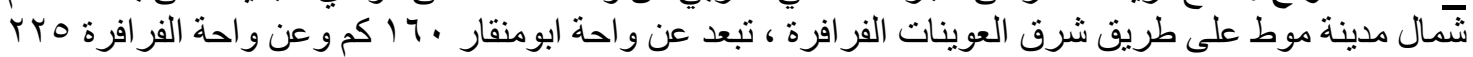

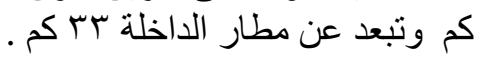

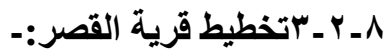

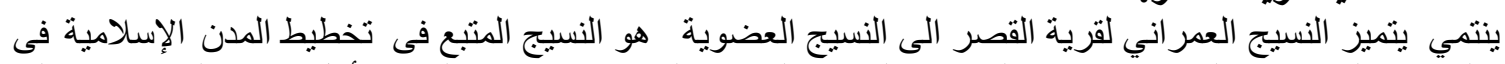

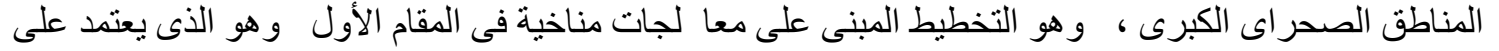

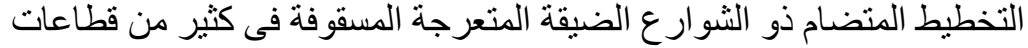

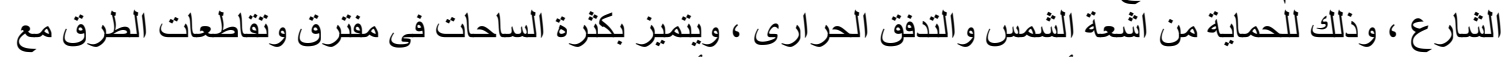

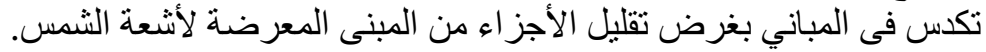
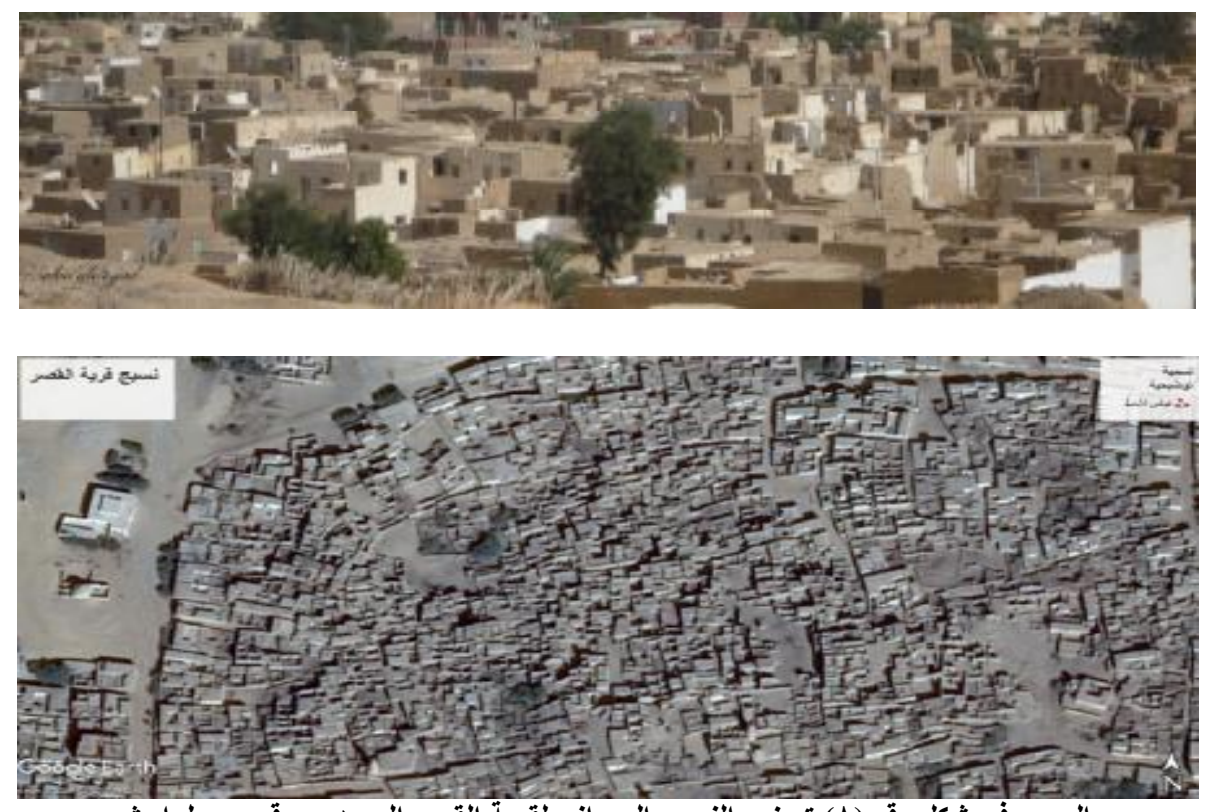

الصور في شكل رقم (^) توضح النسيج العمر انى لقرية القصر المصدر موقع جوجل ارث

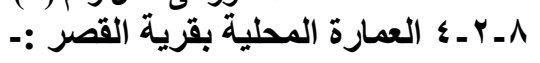

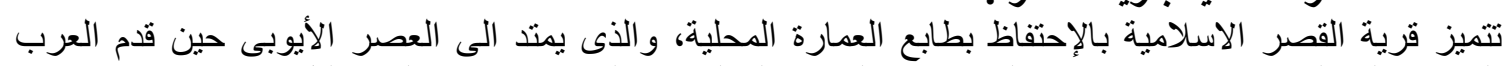

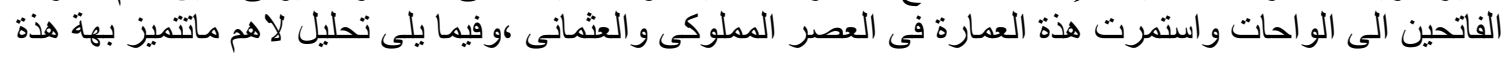

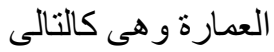

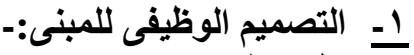

المسقط الافقى يعكس الاحتياجات الوضيفية لسكان الريف المصرى و الو احات بصفة خاصة ويوجد

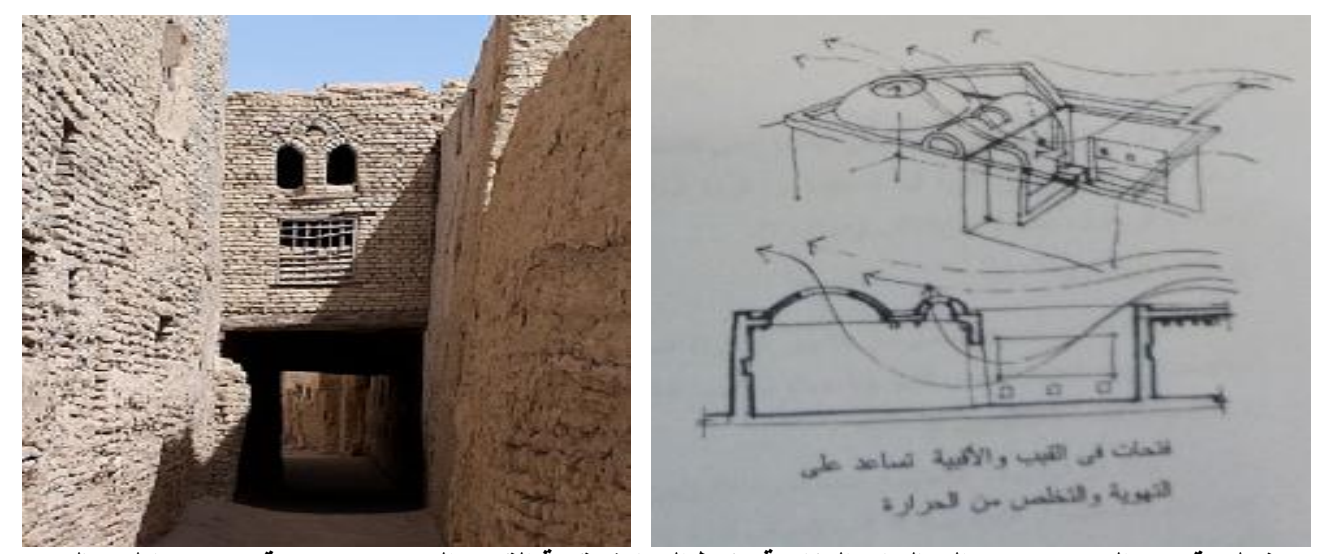

شكل رقم (9) الصور توضح المعالجات المناخية ونمط العمارة بقرية القصر المصدر مرجع رقم (9) (عادل كمال .99 9 (1) ) وموقع الصورمن جوجل ارث

-^_ 


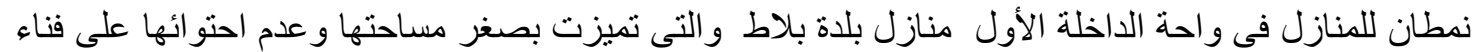

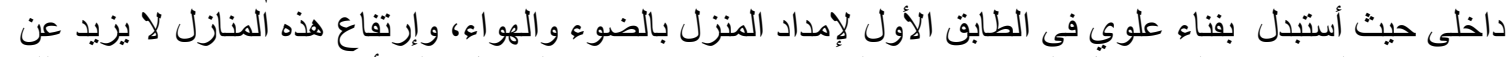

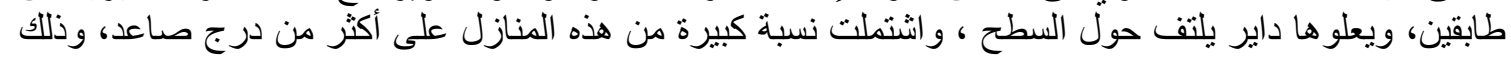

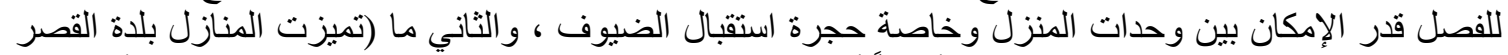

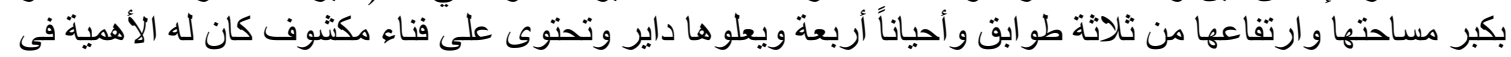

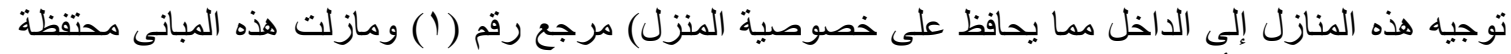

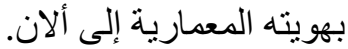

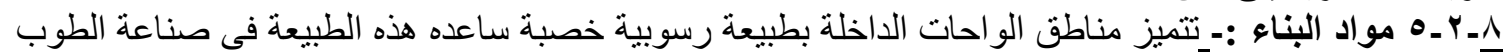

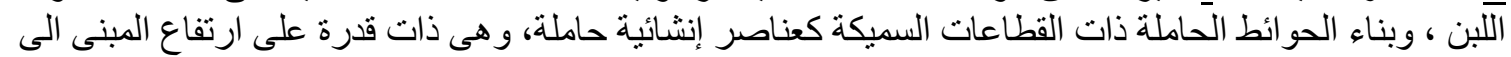

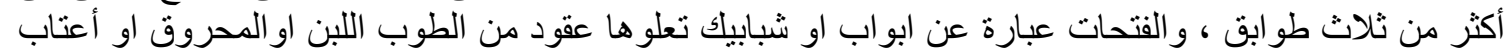

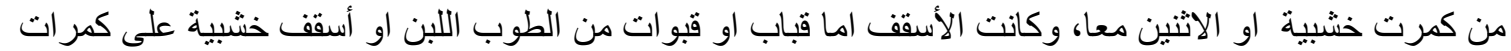

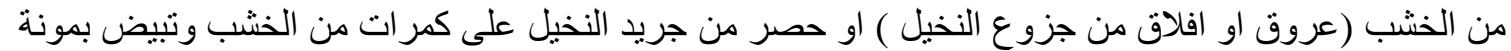

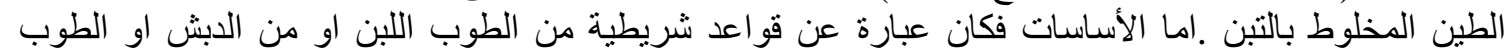

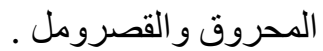

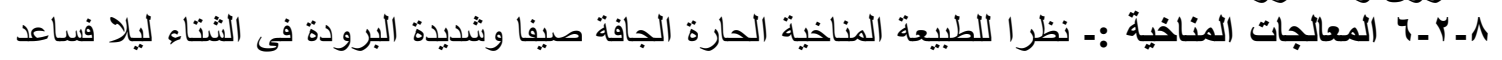

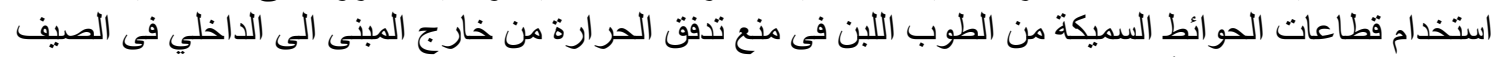

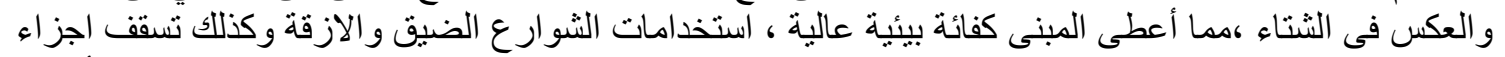

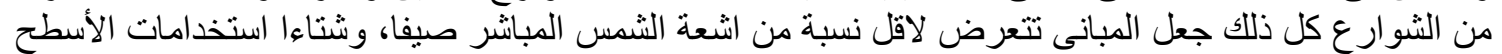

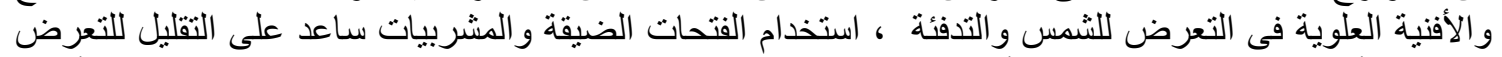

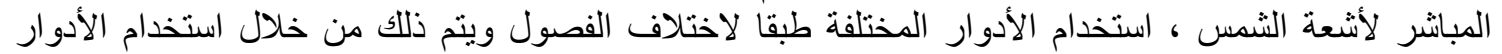

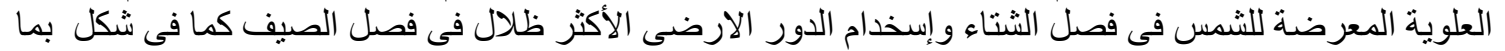
يحقق ظاهرة البداوة اليومية والموسمية (• (1)
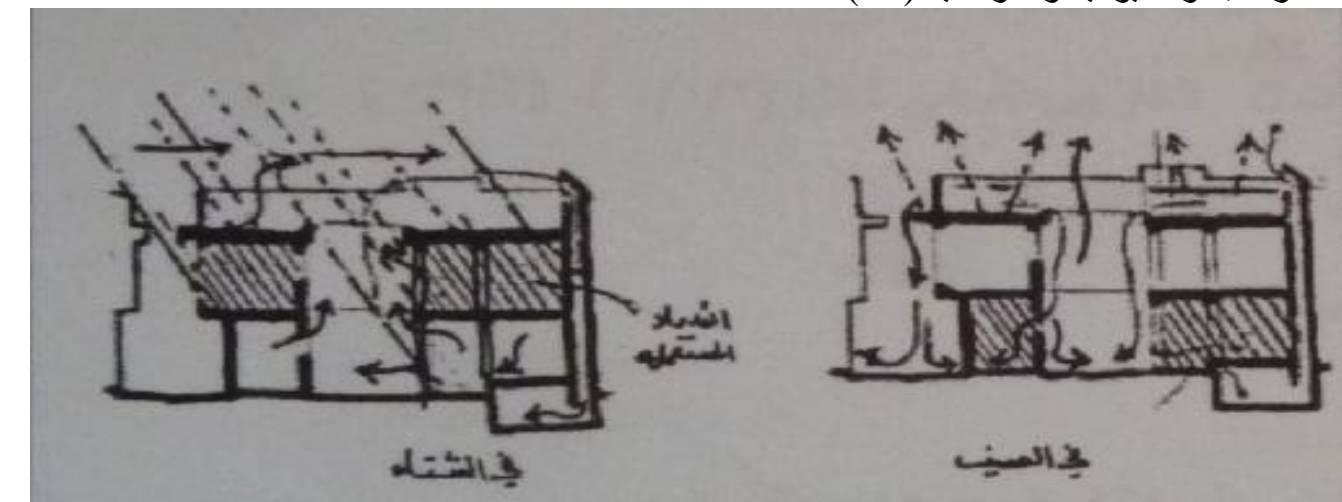

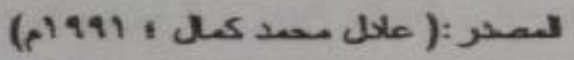

الصورة فى شكل ( • () توضح اسخام ظاهرة البداوى فى مساكن قرية القصر المصدر مرجع رقم (9)(عادل محمد كمال 19 9 ( )

^ ـ ـالحالة الدراسية الثالثة مدينة اجاديس او (اغاديس) دولة النيجر:-

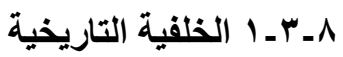

، مدينة اجاديس هى عاصمة الإقليم الثمالي لدولة النيجر وتعتبر من اهم المدن فيهاو البو ابة الثمالية على دول

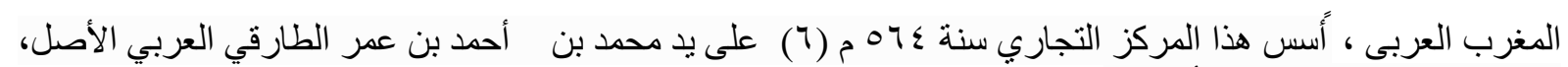

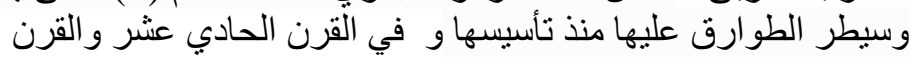

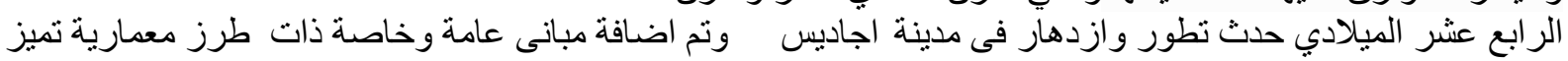

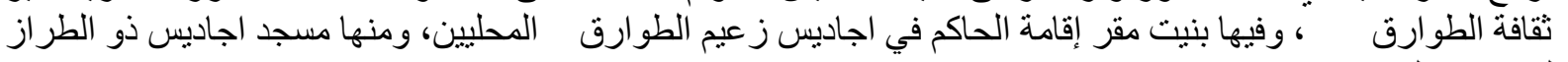
المعمارى المميز. 

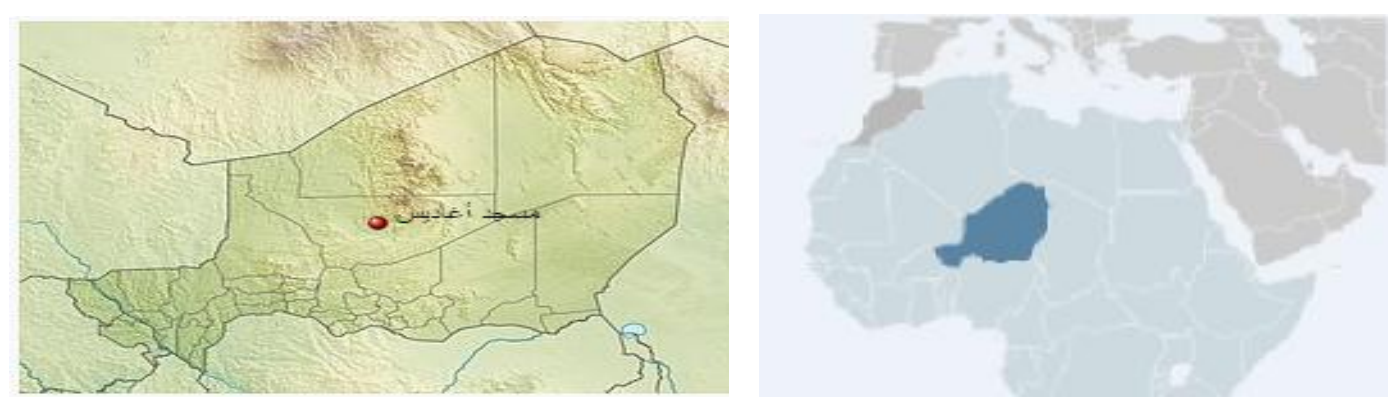

شكل رقم ( 11 ) موقع جمهورية النيجر من شمال افريقيا / ومدينة اجاديس من جمهورية النيجر

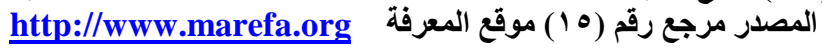

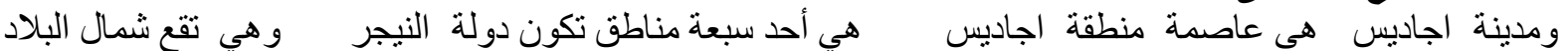

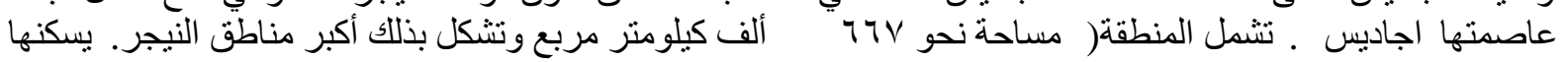

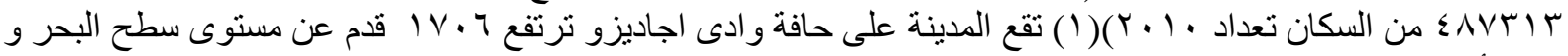

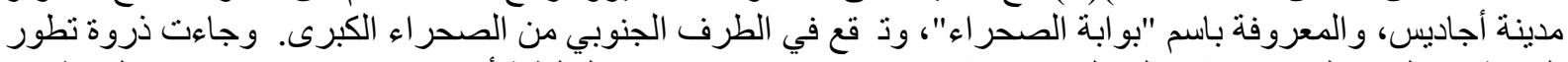

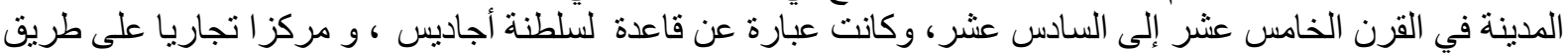

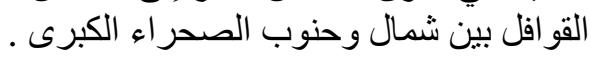

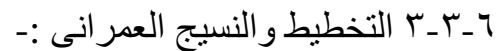

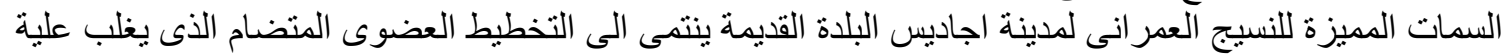

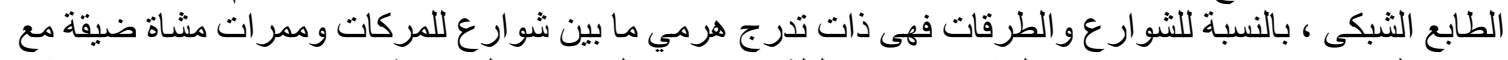

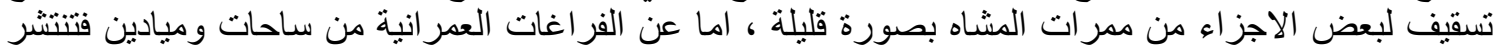

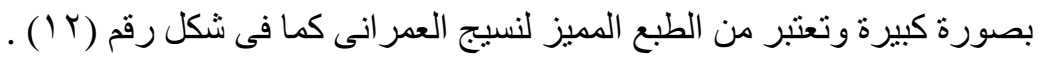

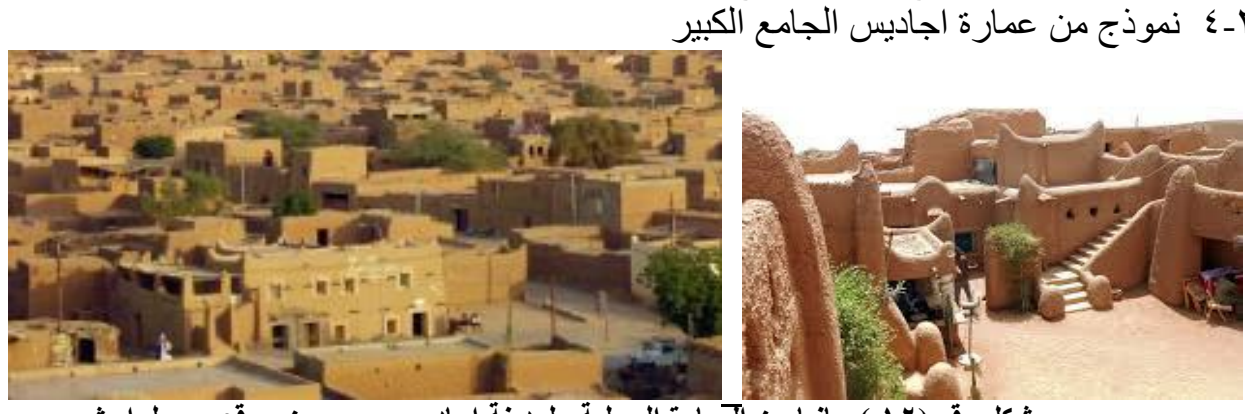

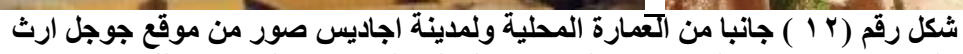

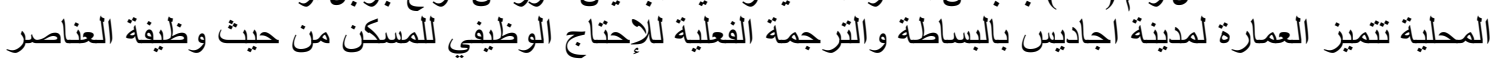

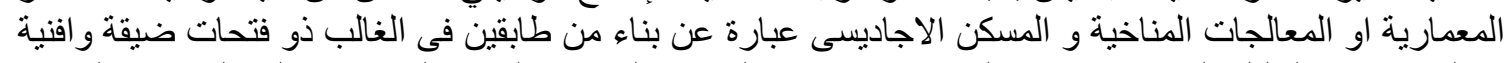

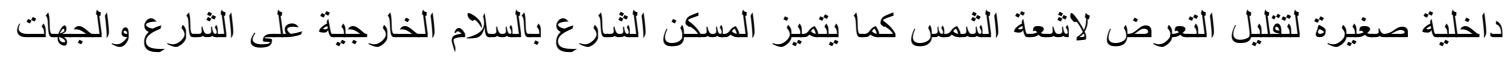

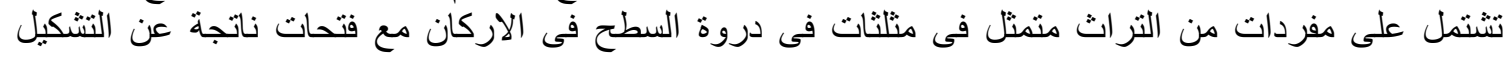

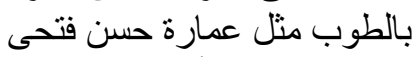

اما عن مسجد أجاديز و هو المعلم الاثرى الاشهر في المدينة ، بنى من الطين عام

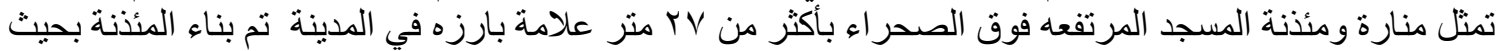

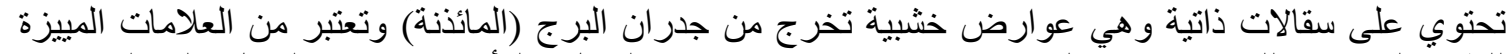

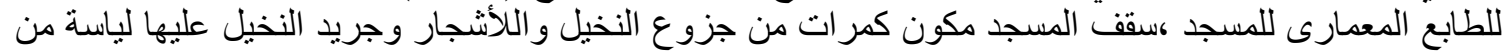

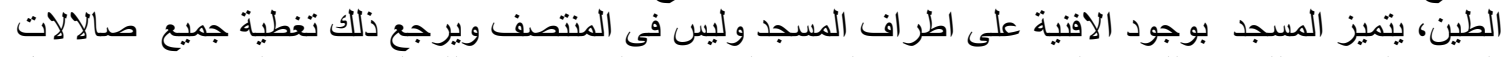

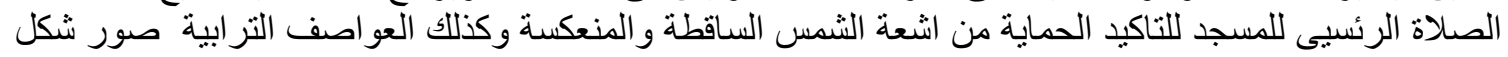
رقم (س I) . 


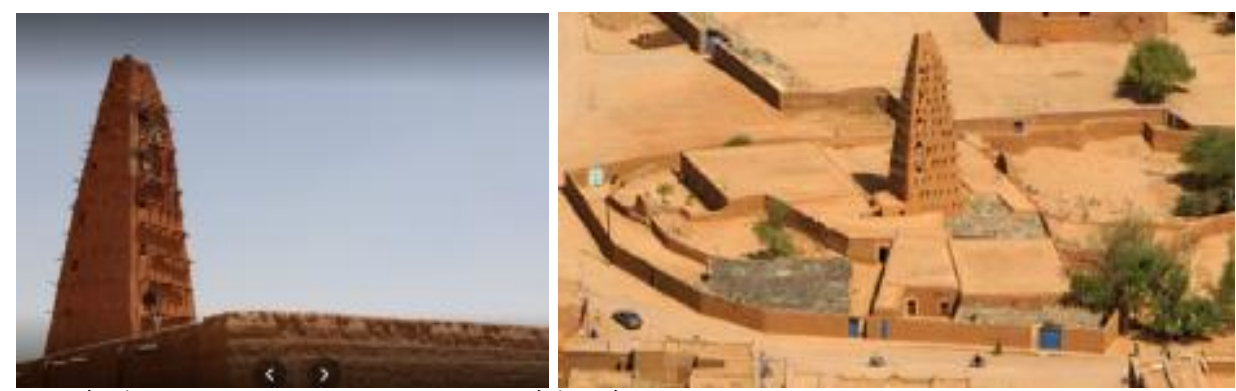

شكل رقم ( r 1 ) موقع عام لمسجد اجاديس / اعمال الصيانة لمئذنة مسجد اجاديس بستخدام السقالات الأتية المصدر موقع جوجل ارثة ماندان

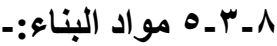

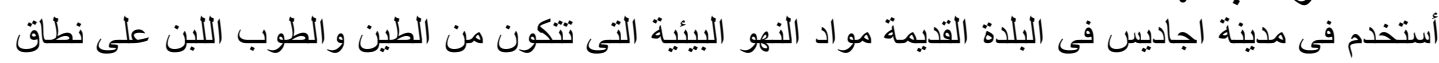

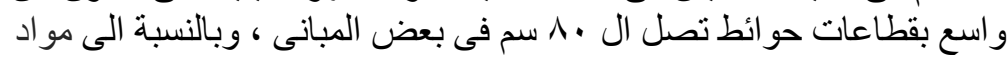

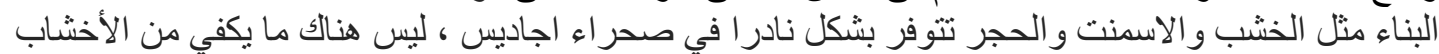

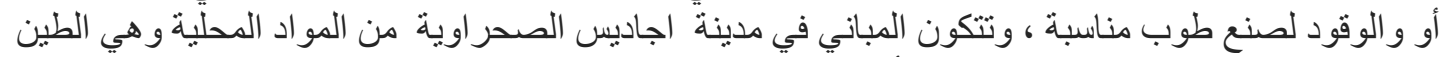

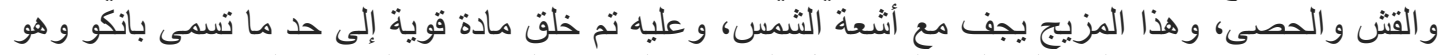

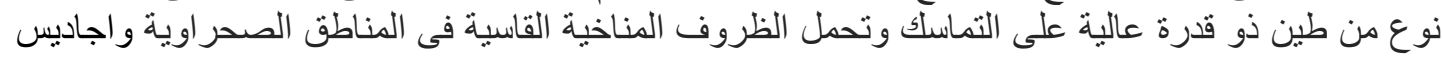

بصفة خاصة .

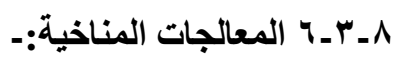

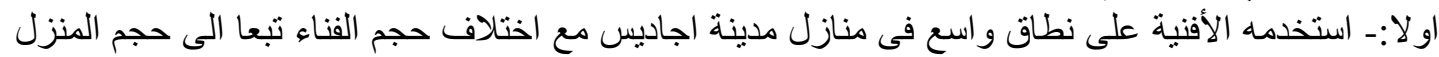
ويتم الاستفادة من قطاعات الحوائط فى تطبيق خاصية التخلف الزمنى حيث يعمل الفئ الفناء على تنظيم عناصر

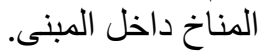
ثانيا:- استخدم البناء بالطين على نطاق واسع و الطوب اللبن لما يتميز به من خصائص بيئي عالية فى العزل

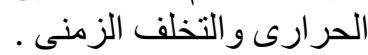
ثالثا :- استخدمة الفتحات الضيقة فى الواجهات الخارجية اللحد من التدفق الحرارى عبر النافذة وكذلك لتحقيق

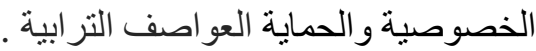
رابعا :- تم عمل سقيفة من جريد النخيل يكون الغرض التراهية الرئيس منها هو الحماية من اشعة الثمس مع امكانية

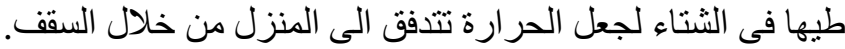
خامسا:- ساهم التخطيط المدمج و المنضام الى توفير اكبر قدر من الظلال وقدرة كبيرة على التى التحكم فى الظروف

المناخية القاسية.

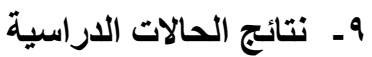 سيمات التراث المعمارى والات العمرانى البيئية فى مناطق الصحراء الكبرى:-}

9 ـــألتخطيط المدمجج

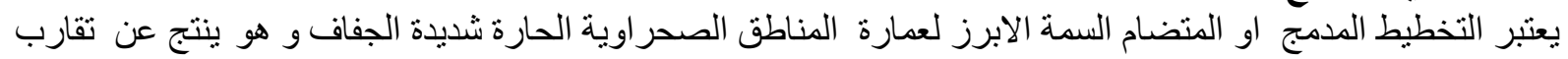

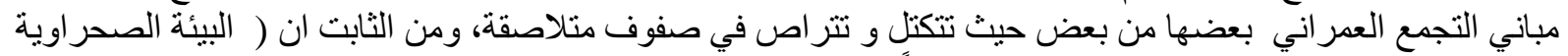

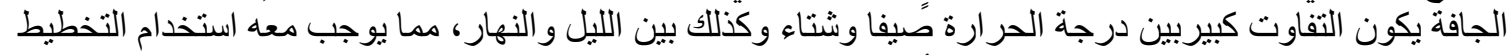

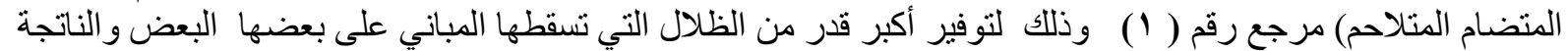

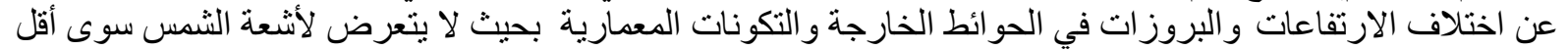

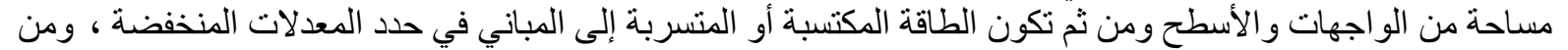

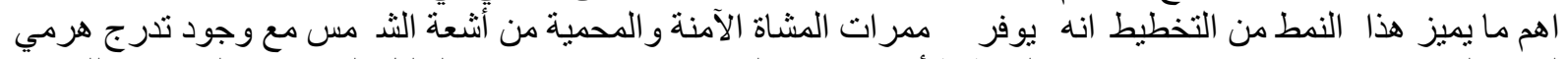

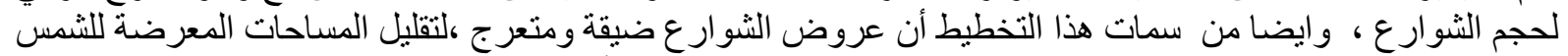

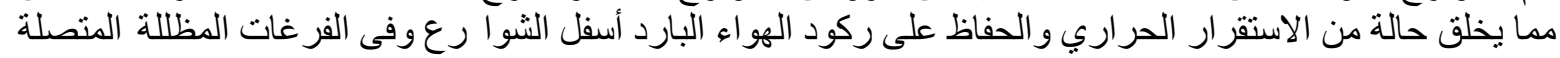

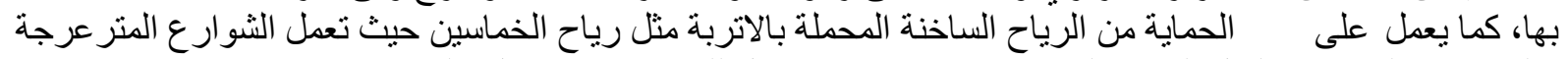

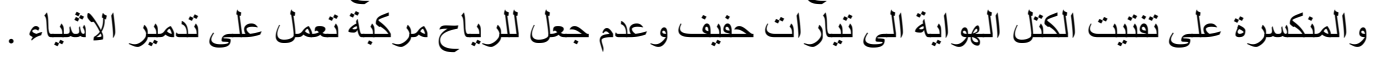

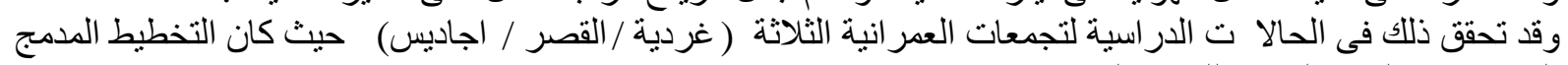

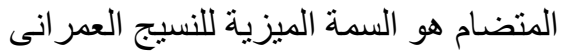




\section{والأمثلة على ذلك كثبر فى اغلب المدن الصحر اوية.}

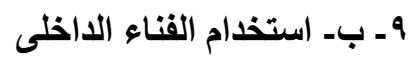

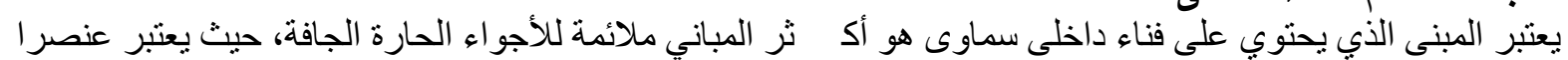

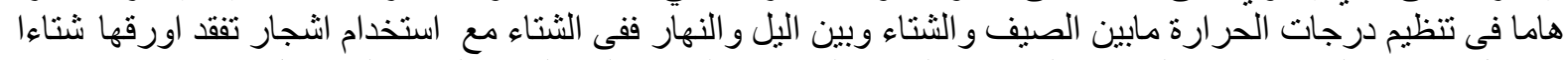

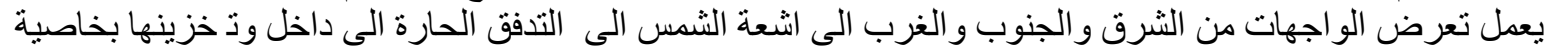

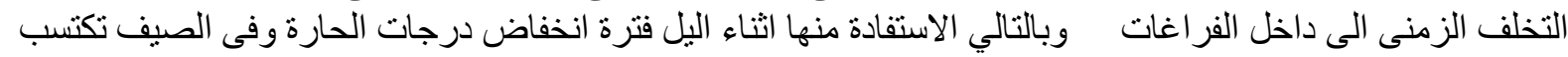

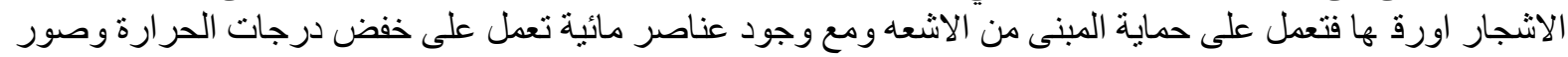

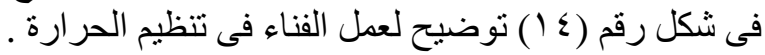

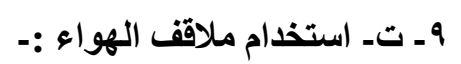

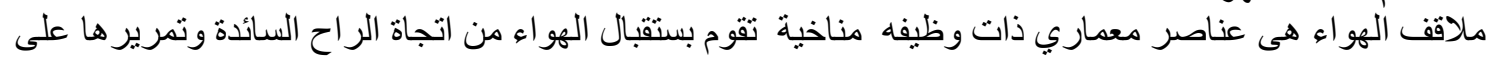

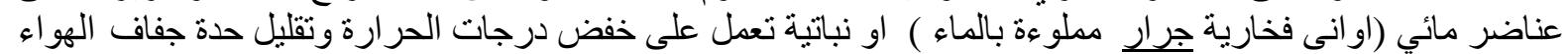
برفع نسبة الرطوب في حدود منطقة الر احنة
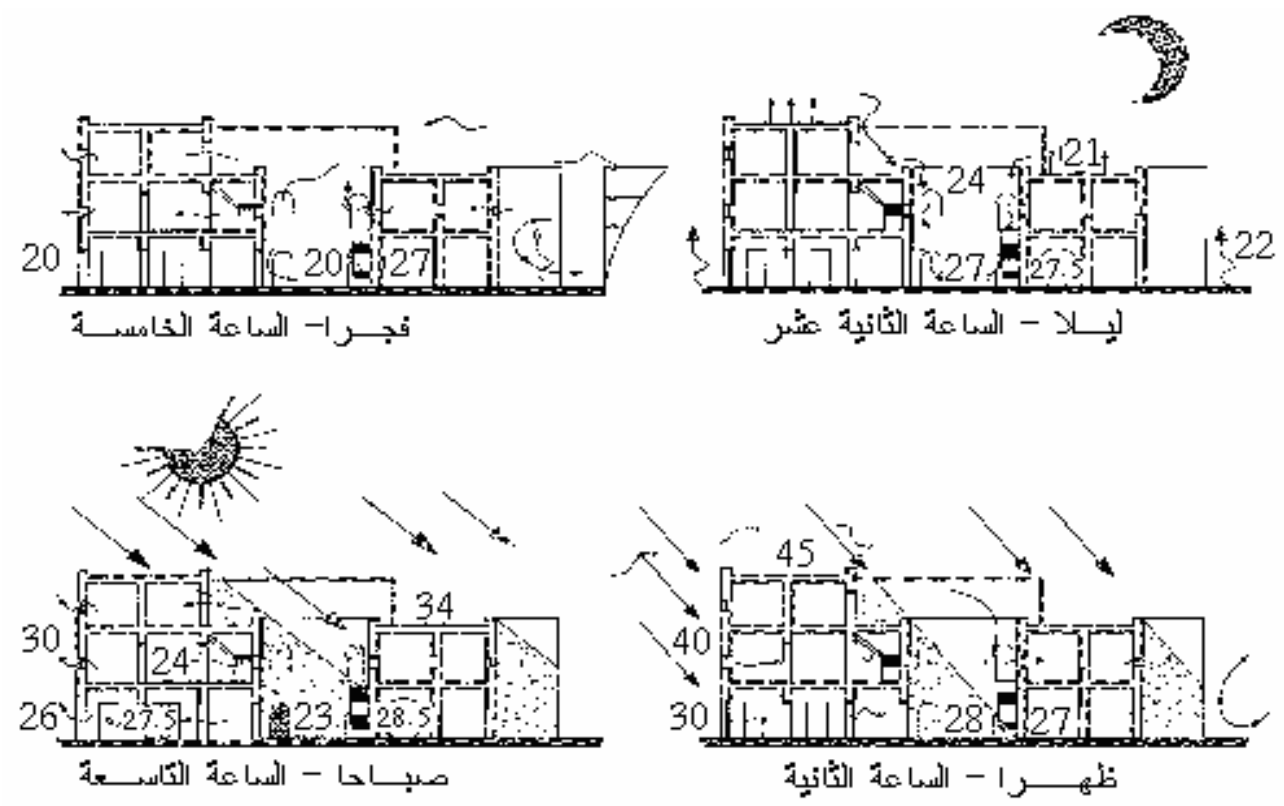

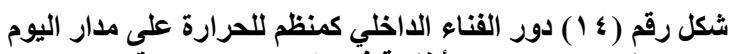

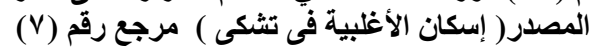

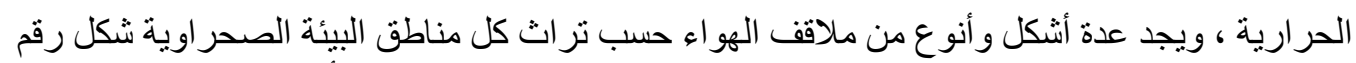

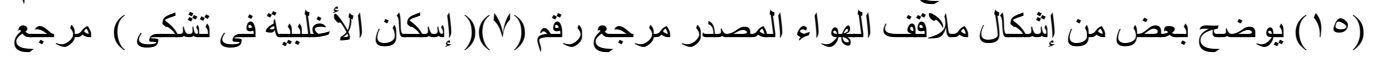
سابق

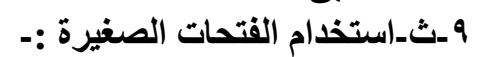

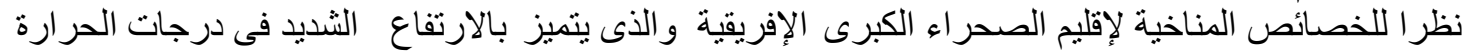

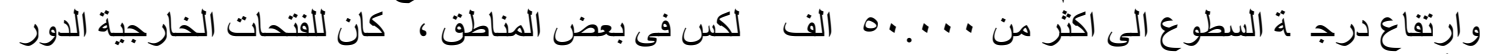

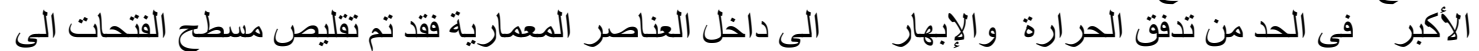

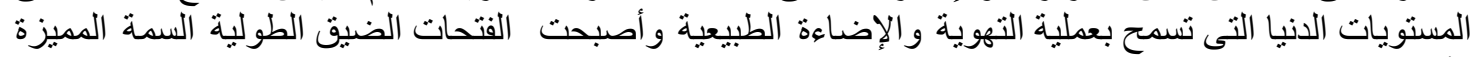

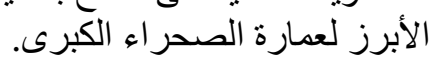




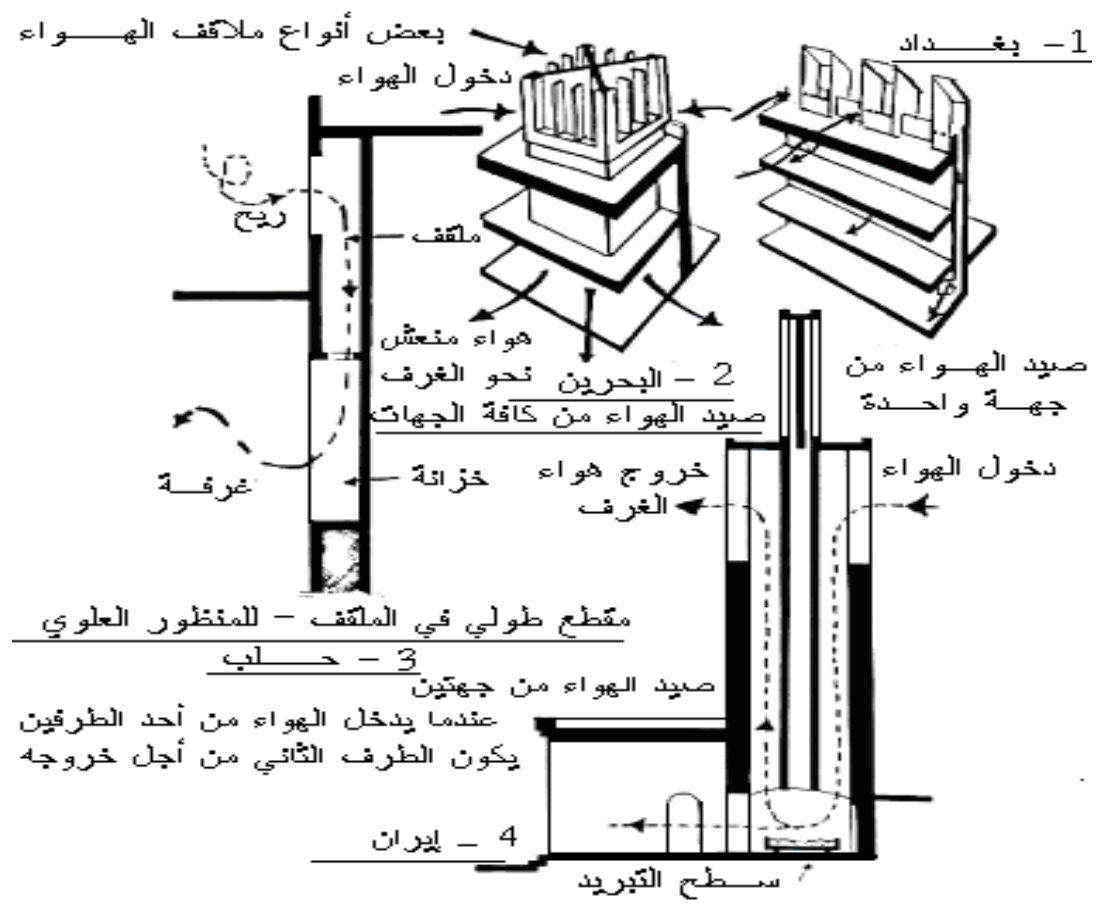

شكل رقم (0 1) يوضح بعض من اشكال ملاقف الهواء المصدر( اسكان الاغلبية فى تثكى ) مرجع رقم (V) ·

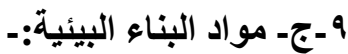

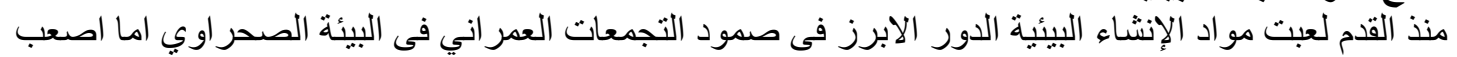

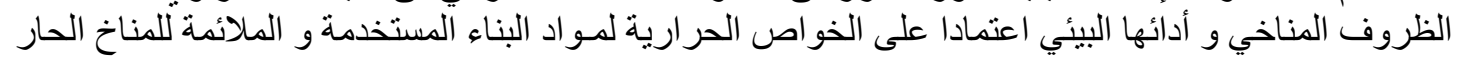

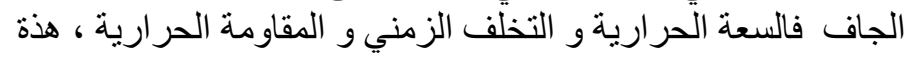

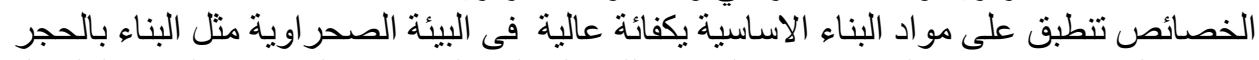

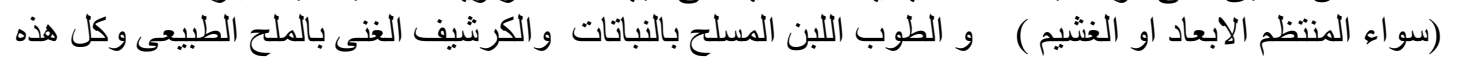

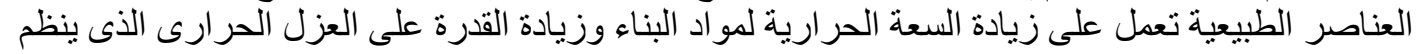

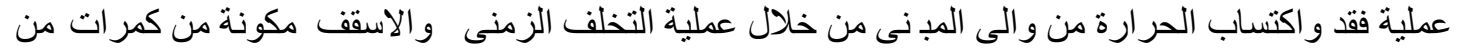

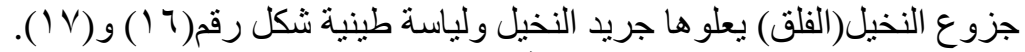

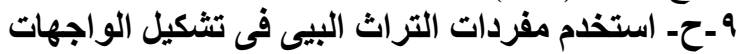

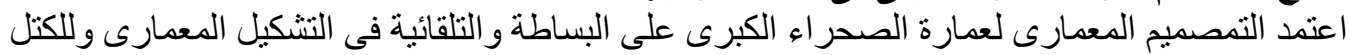

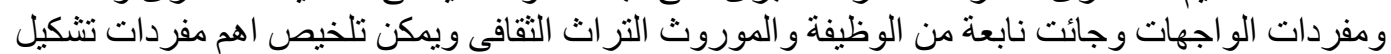

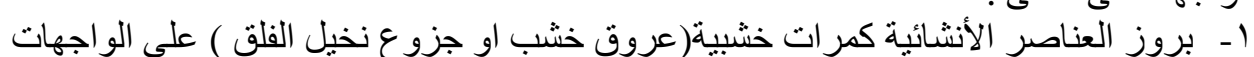

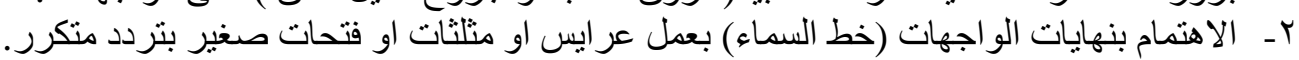

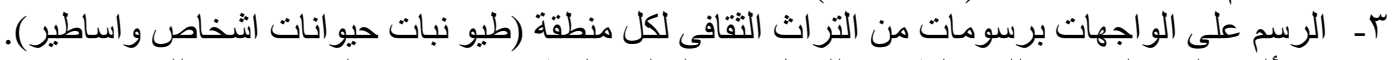
استخدم ألون البيج الغامق (اللون الطبيعى للرمل) فى الغالبية العظمى من مبانى الصحر اء ثُ ثم اللون الأبيض . 
" السمات المشتركة لعمارة الصحر اء الكبرى المدخل البيئي للتصميم فى المناطق الحارة الجافة "

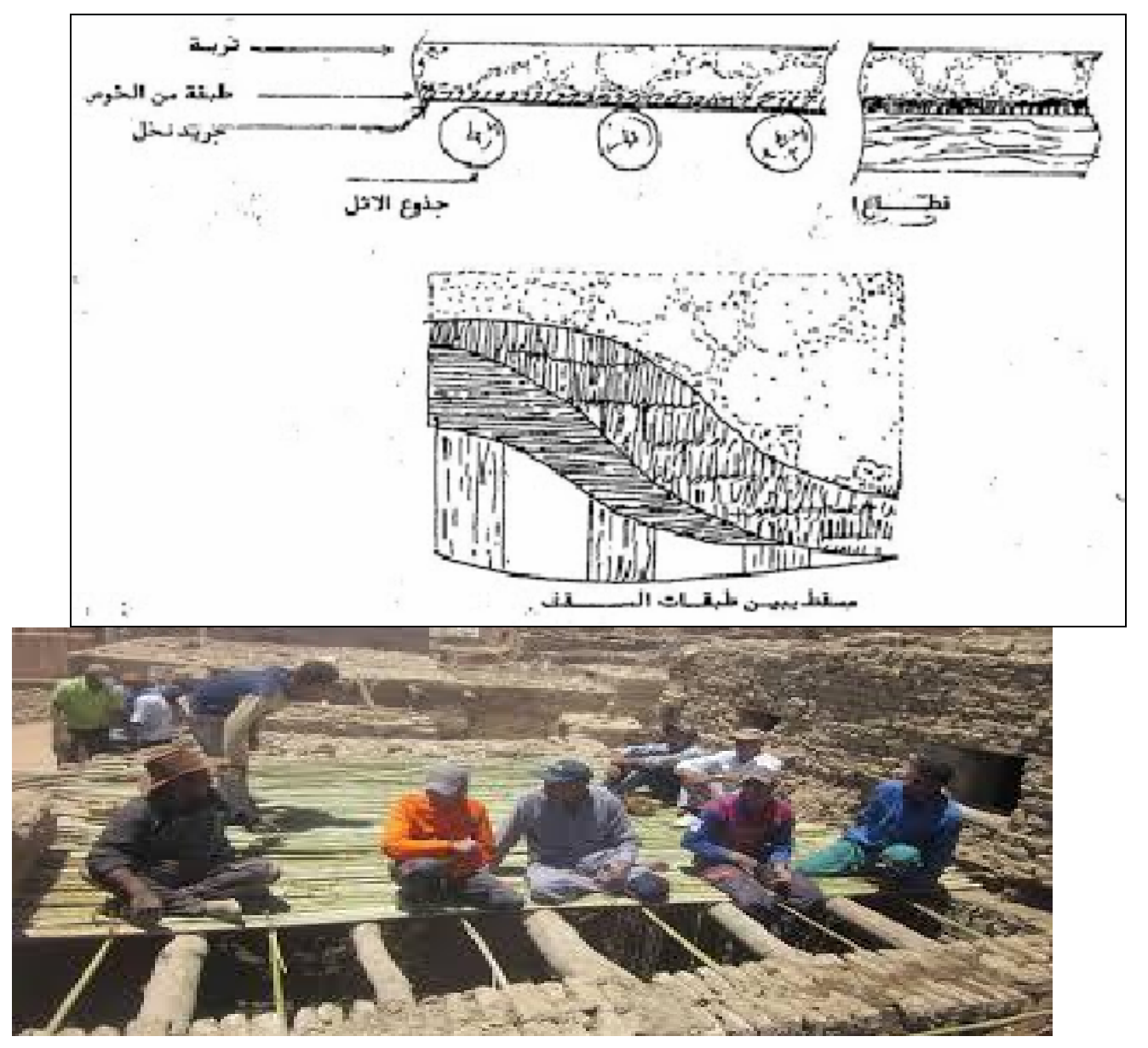

شكل رقم (7 ا ) طبقات الاسقف فى العمارة البيئية الصحراوية المصدر مرجع رقم (r I) مدونة الميراث

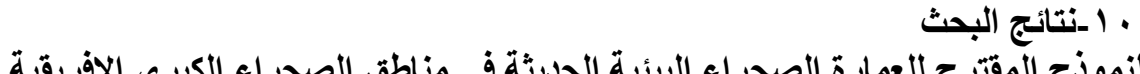

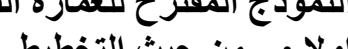
تطوير النسيج ألنظام وألتخطيط المدمج بحث يسمح بمتغير ات العصر من استخدام المركبات داخل النسيح التخطيطى وذلك

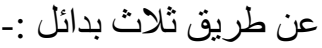

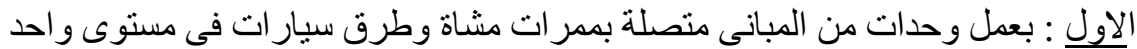

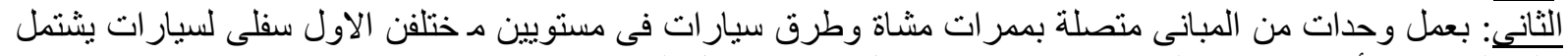

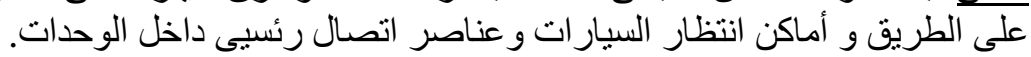

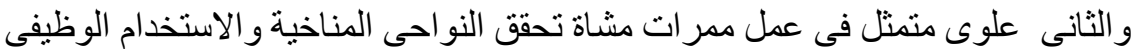

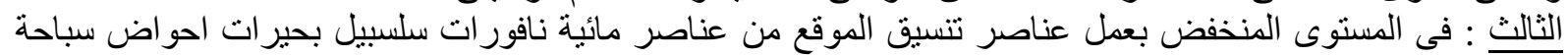

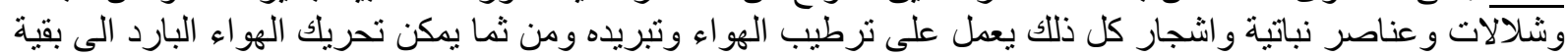
العناصر المعمارية العلوية. ثُانيا :- من حيث التصميم التصنية

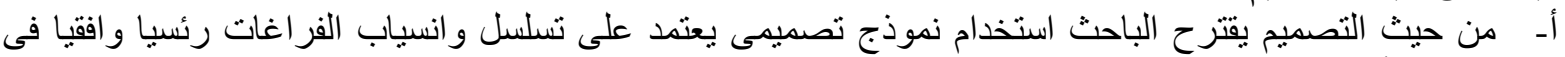

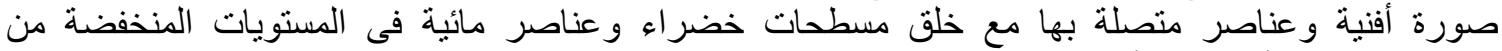

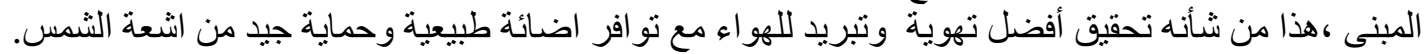

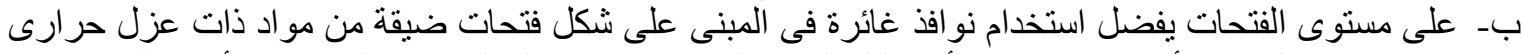

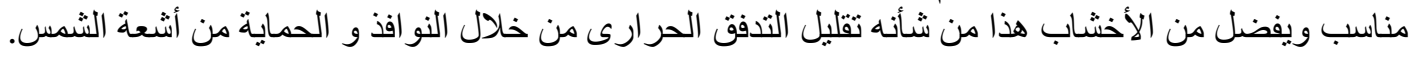




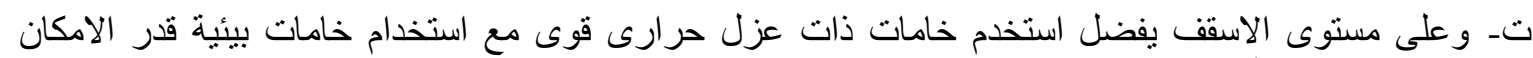

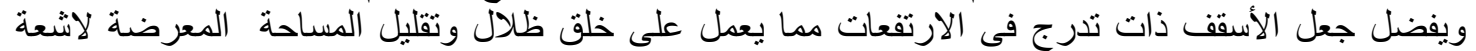

الثمس.

ثـ- يفضل عمال تسقيفات خفيفة من برجو لات من نبات او عناصر خيامية قابلة للفك و التركيب بحيث يتم استخدامها

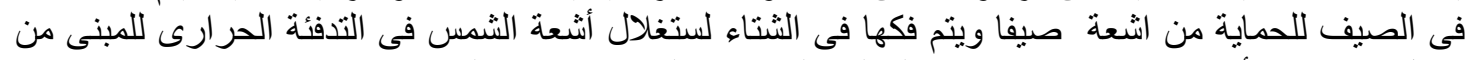
خلال مركبات الأسقف عن طريق خاصية التخلف الزمني و لتحقيق ظاهرة البداوى.

ثالثا :- من حيث استخدام مواد البناء:-

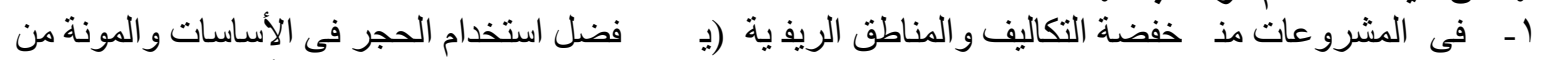

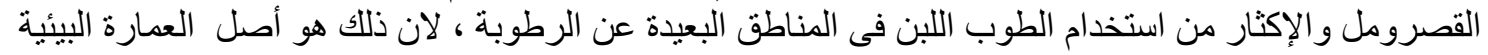

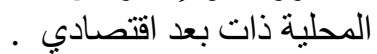

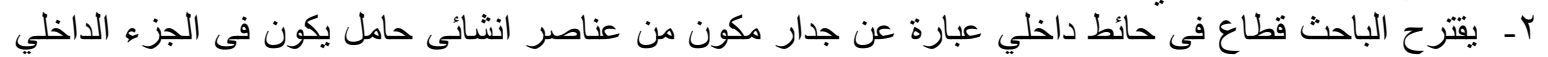

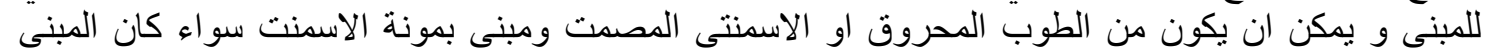

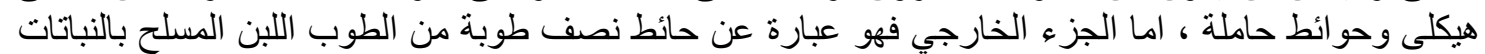

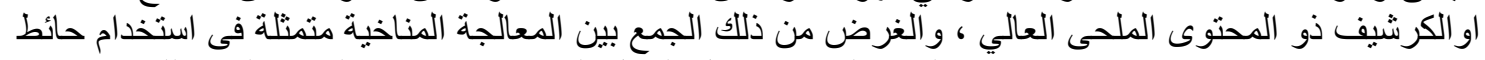

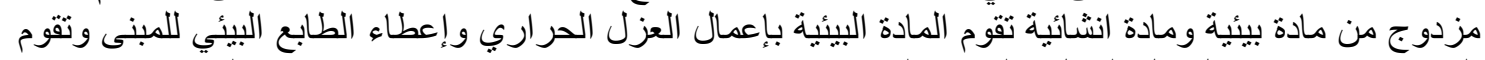

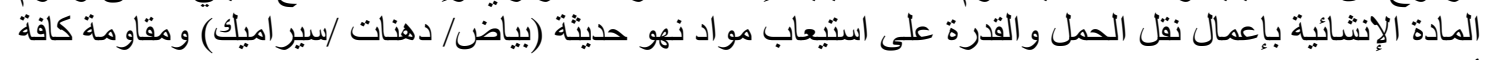

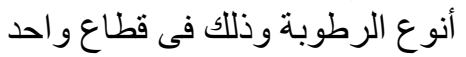

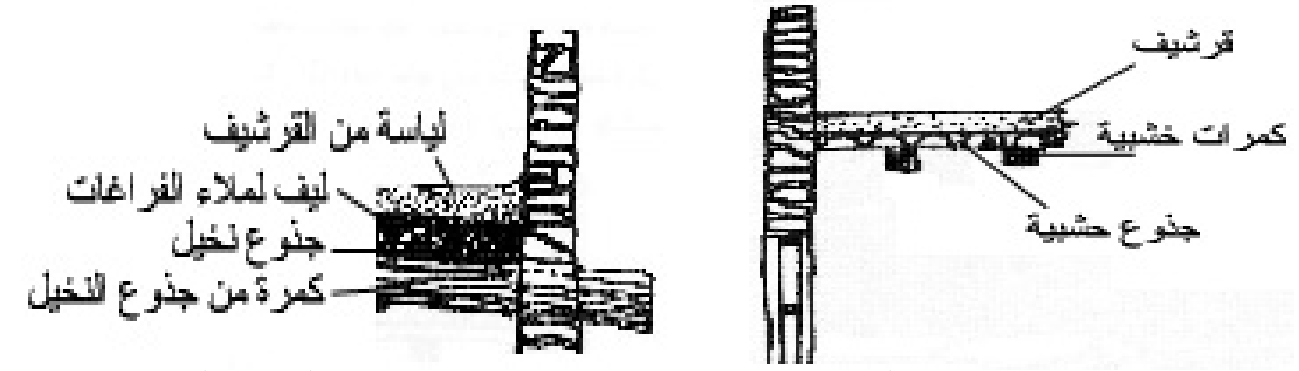

شكل رقم (V ا ) لقطاع فى اشقف عمارة محلية المصدرمرجع رقم (^) إيهاب فاروق راشد "التنمية السياحية....... مرجع سابق صدऍ/؛

رابعا:- من حيث استخدام عناصر ومفردات التراث البيئي

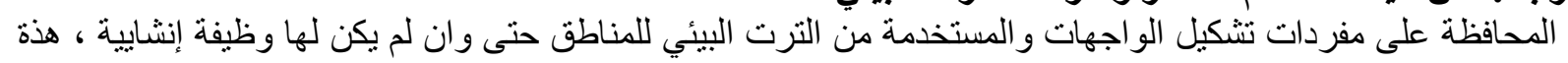

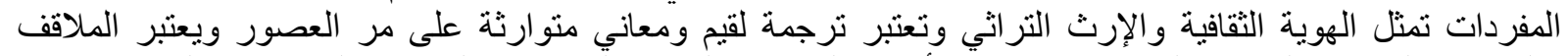

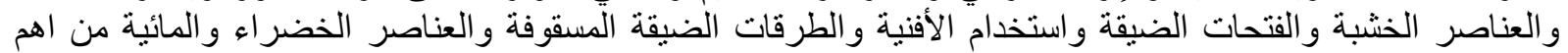
عناصر التراث البيئي فى مناطق الصحر اء الكبرى و على المعماري و المخطط إحياء هذه القئ.

خامسا:- استخدام ظاهرة البداوة فى Nomadism في المسكن الصدمرة الصداوى المعاصر:-

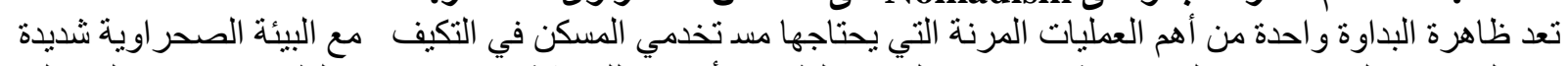

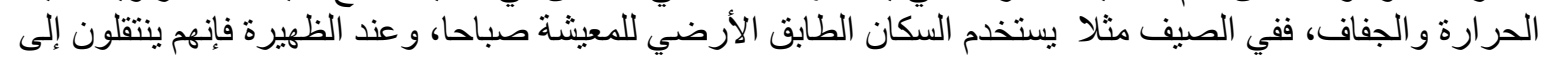

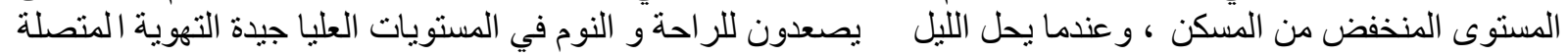

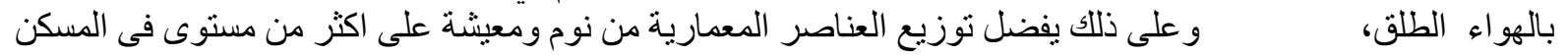

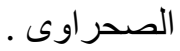
التريات 11

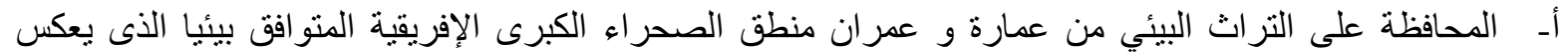

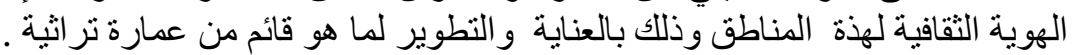

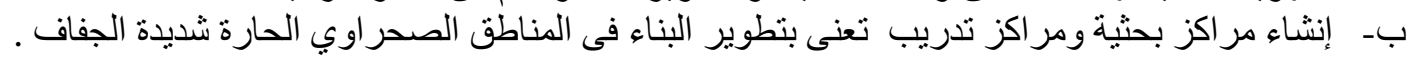

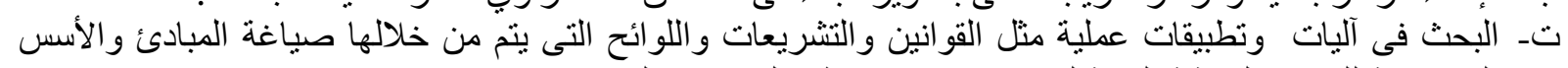

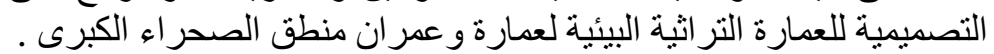

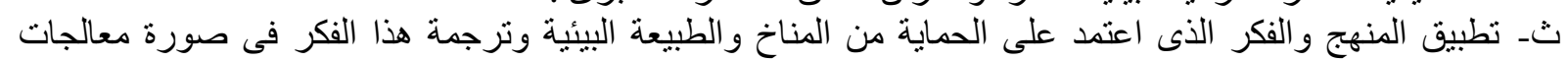

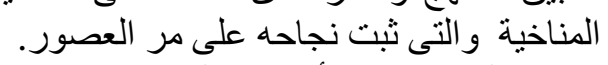

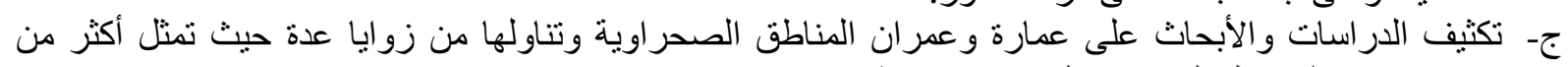
\% \% من مناطق دول الصحر اء الكبرى الإفريقية . 
ا • الوكيل ، العوضى شفق و سر اج عبد الله محمد.(المناخ و عمارة المناطق الحارة) . الطبعة الثالثة 9199 القاهرة،عالم

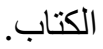

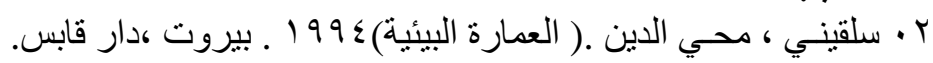

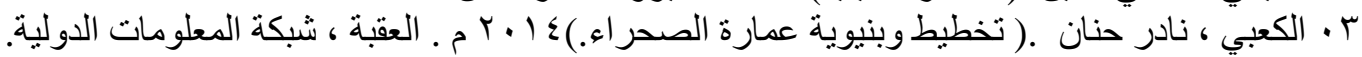

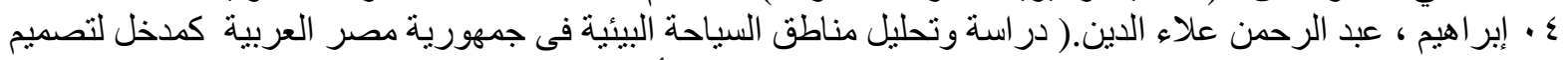

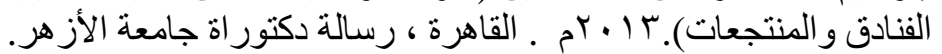

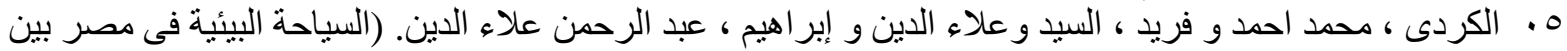

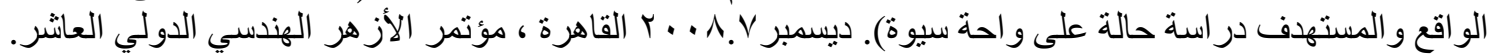

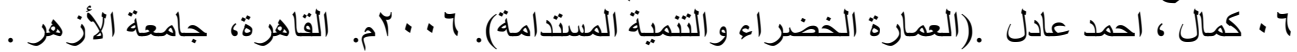

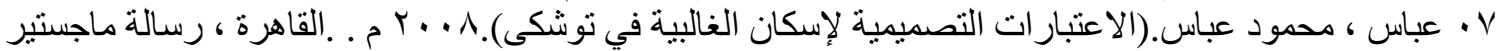
جامعة الأز هر.

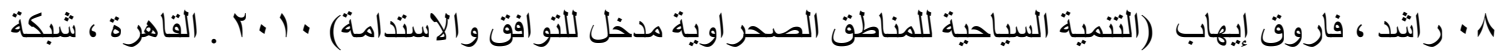

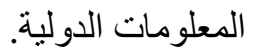

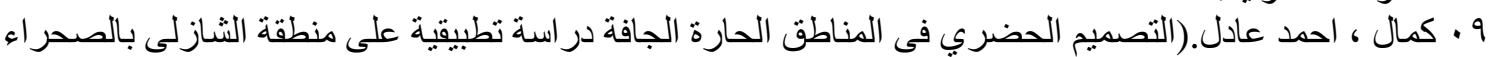

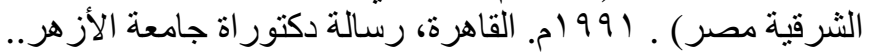

Joe.,Leydey "Elyaqoubi, Description Almaghrib".. 1^60 AL-Rabat . • 1.

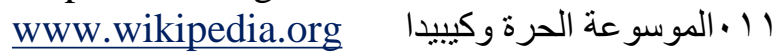

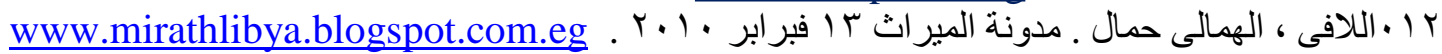

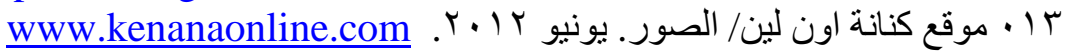

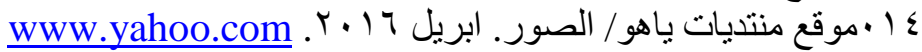

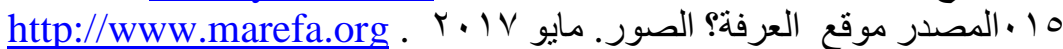

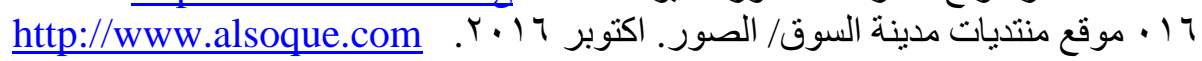

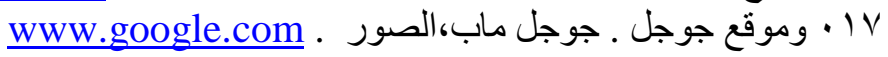

